Original Research Paper

\title{
Lipid composition optimization in spray congealing technique and testing with curcumin-loaded microparticles
}

\author{
G.D Sorita ${ }^{\mathrm{a}, \mathrm{b}}$, A Santamaria-Echart ${ }^{\mathrm{a}}$, A.M Gozzo ${ }^{\mathrm{b}}$, O.H Gonçalves ${ }^{\mathrm{b}}$, F.V Leimann ${ }^{\mathrm{b}}, \mathrm{E}^{\mathrm{B}}$ Bona ${ }^{\mathrm{b}}$, Y Manrique ${ }^{\mathrm{c}}$, \\ I.P.M Fernandes ${ }^{a}$, I.C.F.R Ferreira ${ }^{a}$, M.F Barreiro ${ }^{\text {a,* }}{ }^{a}$ \\ a Centro de Investigação de Montanha (CIMO), Instituto Politécnico de Bragança, Campus de Santa Apolónia, $5300-253$ Bragança, Portugal

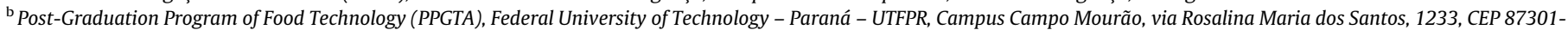 \\ 899, Campo Mourão, PR, Brazil \\ ${ }^{\mathrm{c}}$ Laboratory of Separation and Reaction Engineering - Laboratory of Catalysis and Materials (LSRE-LCM), Faculty of Engineering, University of Porto, Rua Dr Roberto Frias s/n, \\ 4200-465 Porto, Portugal
}

\section{A R T I C L E I N F O}

\section{Article history:}

Received 19 November 2020

Received in revised form 10 March 2021

Accepted 16 March 2021

Available online 2 April 2021

\section{Keywords:}

Lipid-based microparticles

Spray congealing

Simplex-centroid design

Lipid composition optimization

Curcumin

\begin{abstract}
A B S T R A C T
Spray-congealing, a technique based on the fast solidification of sprayed molten lipids, is considered a novel strategy to encapsulate natural products. Among others, it is a safe, low cost, fast and reproducible technique, with rising interest for several applications (e.g. food applications). One of the key parameters for the application of this technique is the lipid solidification temperature, which can be modulated by optimizing the lipid composition. In this work, three lipid components (beeswax, carnauba wax, and medium-chain triglycerides (Miglyol 812)) were selected, and the mixture composition modelled using a simplex-centroid experimental design. Three different lipid compositions were chosen to validate the proposed model, then tested in the preparation of curcumin-loaded microparticles (1.5\%, w/w). The produced microparticles were analysed in terms of colour, morphology, particle size, encapsulation efficiency and load, physicochemical, crystalline, and thermal properties. Results evidenced that microparticle's properties, including encapsulation efficiency, vary according to the used lipid mixture, supporting their tailoring role. This fact brings advantages in the design of microencapsulation systems based on spray congealing processes, broadening their applicability. Moreover, lipid composition optimisation was proved to be an important tool to precede the development of spray-congealing applications. (C) 2021 The Society of Powder Technology Japan. Published by Elsevier B.V. and The Society of Powder Technology Japan. All rights reserved.
\end{abstract}

\section{Introduction}

Spray congealing encapsulation technique is based on the formation of solid microparticles through the atomisation of an active principle dissolved or dispersed in a molten encapsulating material (usually heated $10^{\circ} \mathrm{C}$ above its melting temperature). The spraying of the lipid droplets in a cooling chamber in contact with cold air facilitates the solidification of the system leading to the formation of the final solid microparticles [1]. The strategy avails the preparation of microparticles with controlled size by a simple, fast, and single-step process [2].

Different methodologies can be used to prepare solid lipid particles, including hot melt granulation [3], solvent evaporationbased methods [4] and simple (oil-in-water) or double (waterin-oil-in-water) emulsification processes [5]. These strategies,

\footnotetext{
* Corresponding author.

E-mail address: barreiro@ipb.pt (M.F Barreiro).
}

often require the use of organic solvents or the combination of water and oil phases to induce the formation of the particles. Moreover, they demand multiple process stages including final purification steps. By contrast, just by using a melting/congealing cycle, spray congealing technology offers the possibility to prepare lipid-based tailored particles by cost-effective scalable and continuous manufacturing processes, which can support an easier industrial implementation [6].

Recently, the use of solid lipids as encapsulating materials is being promoted for several applications (e.g. food applications), considering the advantages of these systems prepared by spray congealing technology in comparison with other conventional encapsulation techniques, namely the low cost, safeness, and reproducibility. The fast solidification of the lipid mixtures in contact with cooled air positioned this technique as an attractive via for the preparation of microparticles at relative short process times, and in the absence of solvents [7,8]. It is required the use of lipids solid at ambient temperature, although their mixture with 
liquids (lipids or oils) can also be employed in order to tailor the final properties of the microparticles [9]. Among others, natural waxes such as beeswax or carnauba wax have gained attention to be commercially considered "Generally Recognised as Safe GRAS", ensuring no toxicity while yielding high stability against undesired oxidation processes.

Beeswax, a complex product secreted by bees, whose melting point ranges from 63.5 to $64.5{ }^{\circ} \mathrm{C}$ [10], becomes an attractive candidate for spray congealing processes, as previously reported [11]. Concerning carnauba wax, it shows the highest melting point among vegetal waxes $\left(78-85^{\circ} \mathrm{C}\right)$, being suitable to be employed as an additive for other wax systems (e.g. beeswax), namely to increase the melting point of the final mixture, and thus broaden their application framework [12]. By contrast, the incorporation of liquid lipids, which include digestible oils, including mediumchain triglycerides that generally hold high oxidation stability [13], can decrease the melting point of the mixtures. Miglyol 812 is an attractive medium-chain triglyceride oil, with a structure similar to the one of some solid lipids, facilitating their combination [14], and improving the solubility of the encapsulated active compounds [15] into the system.

Solid microparticles can be employed in several applications, with relevance for the encapsulation of sensitive compounds providing stabilisation and protection for uses, e.g., in the food industry [16]. Curcumin consists in a natural hydrophobic phenolic compound typically used as a natural food colourant [17], presenting other features including antimicrobial [18-22], antiinflammatory [23,24] and anticancer properties [25]. Its inherent colorant characteristics render it an attractive choice for replacing allergenic artificial counterparts [26]. Curcumin is generally associated with poor absorption, low bioavailability, spicy flavour and poor stability against external factors including temperature [27], light [28], air/oxygen [29], pH [30], solvents [31] or storage conditions [32]. Among others, it should be noted the sensitivity of curcumin to heating treatments [33], considered as a limiting factor for, e.g., use in food applications needing cooking stages in ovens (e.g. pastry or bakery products). In this context, providing protection through encapsulation into solid lipid-based matrices, which are characterized by presenting temperature resistance, can be envisaged as a promising tool to overcome these constraints.

In this work, beeswax, carnauba wax and miglyol 812 were chosen as the components to prepare lipid mixtures to be used in spray-congealing. Initially, and based on a design of experiments approach, the working space for the mixture composition was defined considering the solidification temperature as the response, a key parameter to employ spray congealing technique. Afterwards, three compositions were employed for model validation and used to prepare curcumin-loaded microparticles $(1.5 \%, \mathrm{w} / \mathrm{w})$. The obtained curcumin-loaded microparticles were compared against control samples (microparticles without curcumin). The properties of the microparticles were analysed in terms of colour, morphology, particle size, physicochemical, thermal and crystalline properties. To the best of our knowledge, optimization of the lipid composition to attain a suitable solidification temperature in spray congealing was not previously reported, neither the use of this technique to encapsulate curcumin, technique that presents several advantages over the traditionally employed hot melt dispersion technique. In fact, works involving solid lipid matrices, including the ones produced by spray congealing [4] or alternative methods [34,35], were mainly focused on the encapsulation of pharmaceuticals or drugs for delivery applications [36], but not on natural bioactives and/or colorants, namely curcumin. Moreover, the optimization of the system through the use of experimental design strategies, provides a predictive tool to validate new lipid formulations, positioning the present work as an innovative strategy in comparison to other works where formulations
$[37,38]$ or spray congealing process parameters [4] are tested by conventional trial/error methods.

\section{Experimental}

\subsection{Materials}

Curcumin (85\% purity) was acquired from Sigma-Aldrich and stored protected from light until use. Beeswax (100\% purity, Acros Organics), carnauba wax (100\% purity, Acros Organics) and medium-chain triglycerides (Miglyol 812 a mixture of capric and capric acid esters supplied by Oleochemicals) were used as the encapsulant base materials to prepare the lipid mixtures.

\subsection{Optimisation of the lipid mixture composition}

The lipid mixture composition, further used in the testing of the preparation curcumin loaded microparticles by spray congealing technique, was optimized by a simplex-centroid design with axial points considering ternary mixtures that include beeswax (BW), carnauba wax (CW) and miglyol (M). Attending to the restrictions involved in the mixture formulation (it must be solid at ambient temperature), a minimum beeswax concentration of $40 \%$ and maximum miglyol concentration of $60 \%$ were defined, considering that liquid mixtures were obtained at $20^{\circ} \mathrm{C}$ out of this range in preliminary tests. The mixtures maximum melting temperature was established at $70{ }^{\circ} \mathrm{C}$, which was established based on the spray congealing equipment restrictions. The number of experiments/ replicas in the experimental design was planned to include the repetition of the centre point (4 replicas) avoiding the need of replicating all the samples. This is the number of replicas required in the Simplex-centroid experimental design. This assumption takes into consideration that homoscedasticity was valid within the experimental range, meaning that variance was equal in all experimental points [39].

The three evaluated variables, namely the concentration of each lipid in the prepared mixtures was expressed in terms of pseudo components mass fractions [40], and referred as beeswax ( $\left.\mathrm{X}_{\mathrm{BW}}\right)$, carnauba wax $\left(\mathrm{X}_{\mathrm{CW}}\right)$ and miglyol $\left(\mathrm{X}_{\mathrm{M}}\right)$, considering the total mass equal of the sample equal to $1 \mathrm{~g}$. The response for the design was defined as the solidification temperature (Ts) of the mixture, which was determined by dynamic scanning calorimetry (DSC) according to the protocol described by Guimarães-Inácio et al. [41] as described next in Section 2.4.

The simplex-centroid experimental design was adjusted to a cubic model according to Eq. (1) [42], where $\widehat{y}$ represents the evaluated response, namely solidification temperature; $\beta_{i}$ the regression coefficient; $X_{i}$ the pseudo components relative to beeswax $\left(\mathrm{X}_{1}\right)$, carnauba wax $\left(\mathrm{X}_{2}\right)$, and miglyol $\left(\mathrm{X}_{3}\right)$.

$\hat{y}=\beta_{1} \cdot X_{1}+\beta_{2} \cdot X_{2}+\beta_{3} \cdot X_{3}+\beta_{12} \cdot X_{1} \cdot X_{2}+\beta_{13} \cdot X_{1} \cdot X_{3}+\beta_{23} \cdot X_{2} \cdot X_{3}+\beta_{123} \cdot X_{1} \cdot X_{2} \cdot X_{3}$

The model was evaluated by the coefficient of determination $\left(R^{2}\right)$, adjusted coefficient of determination $\left(R_{\mathrm{adj}}^{2}\right)$ and ANOVA with lack of fit. Triangular contour plot was used to represent the results for each dependent variable, based on the models adjusted using Statistica 13 software.

\subsection{Validation of the model}

The validation of the model was assessed by analysing three mixtures included in the designed framework space. The validation samples were selected according to two criteria, including the solidification temperature and particles' composition. The solidification temperature range was adjusted to the limitations of the 
equipment, being determined according to the previously stated protocol. The selection of the mixtures' composition took into consideration the combination of different lipids to achieve different compositions. Model validation was done by comparing the solidification temperatures of the mixtures with the confidence interval predicted by the model.

\subsection{Microparticles preparation by spray congealing technique}

Microparticles were prepared by the spray congealing technique using a Mini Spray Dryer B-290 Buchi (Flawil, Switzerland) according to the following atomisation conditions: atomiser nozzle diameter of $0.7 \mathrm{~mm}$ (providing a particle diameter in the range between 20 and $200 \mu \mathrm{m}$ ), an inlet temperature of $140{ }^{\circ} \mathrm{C}$, an outlet temperature of $10^{\circ} \mathrm{C}$, a cooling airflow rate of $37,500 \mathrm{~L} / \mathrm{h}$, and $100 \%$ of aspiration. The same conditions were chosen for all the atomized samples to avoid processing conditions variability among samples. The three lipid mixture formulations used for the validation of the experimental design model were used to produce the microparticles. For each lipid composition, a control sample (microparticles without curcumin), and the corresponding microparticles loaded with $1.5 \%(\mathrm{w} / \mathrm{w})$ of curcumin were prepared. Before atomization, the lipids were heated at $100{ }^{\circ} \mathrm{C}$ under magnetic stirring for 10 min followed by curcumin adding, in the case of the loaded microparticles. To guarantee the liquid state from the reservoir until the atomisation point, the mixtures were maintained at $100{ }^{\circ} \mathrm{C}$ for an additional timeframe of $10 \mathrm{~min}$. After the atomisation process the obtained microparticles were stored at $-4{ }^{\circ} \mathrm{C}$ protected from light until characterisation.

\subsection{Microparticles characterisation}

The microparticles were characterised by Colourimetry, Scanning Electron Microscopy (SEM), Laser Diffraction (size analysis), Fourier Transform Infrared Spectroscopy (FTIR), Differential Scanning Calorimetry (DSC), and X-Ray Diffraction (XRD). For comparison purposes, physical mixtures mimicking the composition of the loaded microparticles were prepared and analysed by FTIR, DSC and XRD. Encapsulation efficiency (EE) and load capacity (LC) of the microparticles was determined by ultraviolet spectroscopy (UV).

The colour of the microparticles was evaluated by determining the CIELAB parameters ( $\mathrm{L}^{*}, \mathrm{a}^{*}$ and $\mathrm{b}^{*}$ ) using a colourimeter CR-400 model, Konica Minolta Sensing Inc., Japan equipment. Parameters were directly determined by reflectance measurements in triplicate.

The morphology of the microparticles was assessed by SEM using a Phenon Pro microscope from Phenom World (Eindhoven, The Netherlands) with a backscattered electron detector. Samples were analysed with a magnification of 500x and 2500x (acceleration voltage of $15 \mathrm{kV}$ ) and supported on carbon sheets. As well, a Temperature Controlled Sample Holder (TCSH), which adjusted temperature easily and quickly based on the Peltier principle, was used to control the temperature of the sample and minimize the effect of the electron beam and vacuum damage.

The particle size distributions of the microparticles was determined by Laser Diffraction using a Malvern Mastersizer 3000 equipped with a dispersion unit (Malvern, Hydro MV) (Worcs, UK). Samples were analysed averaging five replicates at $25^{\circ} \mathrm{C}$ using distilled water as the dispersant medium.

Structural analysis including the established interactions among the used components (carnauba wax, beeswax and curcumin), in the microparticles and physical mixtures, were analysed by FTIR using a MB300 (ABB, Zurich, Switzerland) apparatus in attenuated reflectance mode. Samples were recorded by averaging 32 scans with a resolution of $16 \mathrm{~cm}^{-1}$ in the range between 4000 and $550 \mathrm{~cm}^{-1}$. Spectra were treated with Horizon MB software version 3.4 and normalised using the highest intensity peak for comparison purposes.

The thermal behaviour of constituents (carnauba wax, beeswax and curcumin), physical mixtures and microparticles was determined by DSC using a Netzsch, DSC 204 F1 Phoenix equipment (Selb, Germany). Around 5-10 mg of the sample was weighted into closed aluminum crucibles and submitted to a dynamic scan from 0 to $250{ }^{\circ} \mathrm{C}$ at $10^{\circ} \mathrm{C} /$ min under nitrogen atmosphere $(20 \mathrm{~mL} / \mathrm{min})$. The solidification temperature of the mixtures (response of the experimental design) was determined according to the protocol reported by Guimarães-Inácio et al. [41]. For this purpose, samples were prepared by weighting the corresponding components to a test tube, thereafter mixed, and placed in an oil thermostatic bath (NAHITA model 602/6) at $90{ }^{\circ} \mathrm{C}$ for $10 \mathrm{~min}$ under vigorous agitation. The tubes were rapidly cooled to $-20{ }^{\circ} \mathrm{C}$ to promote the solidification of the mixture, and then maintained at this condition for $1 \mathrm{~h}$ before analysis. The resultant mixtures (approximately $10 \mathrm{mg}$ ) were subjected to an initial heating scan from -80 to $100{ }^{\circ} \mathrm{C}$ at $10^{\circ} \mathrm{C} / \mathrm{min}$. After maintaining the temperature at $100{ }^{\circ} \mathrm{C}$ for $10 \mathrm{~min}$, the samples were cooled to $0{ }^{\circ} \mathrm{C}$ at $20^{\circ} \mathrm{C} / \mathrm{min}$ and kept at $0{ }^{\circ} \mathrm{C}$ for $10 \mathrm{~min}$. A second heating scan was carried out from 0 to $150{ }^{\circ} \mathrm{C}$ at $10{ }^{\circ} \mathrm{C} / \mathrm{min}$, followed by keeping at $150{ }^{\circ} \mathrm{C}$ for $5 \mathrm{~min}$ and cooling to $0{ }^{\circ} \mathrm{C}$ at $20{ }^{\circ} \mathrm{C} / \mathrm{min}$. The solidification temperature was determined from the second cooling thermograms.

The crystallinity of the constituents (beeswax, carnauba wax and curcumin), and of microparticles, were determined by XRD in a Bruker D8 Advance equipment. The analysis was carried out using $\mathrm{Cu}-\mathrm{K} \alpha$ radiation at $40 \mathrm{KV}$ and $35 \mathrm{~mA}$ from $3^{\circ}$ to $40^{\circ}(2 \theta)$ at $5.9^{\circ} / \mathrm{min}$.

The encapsulation efficiency (EE) and load capacity (LC) of curcumin in the microparticles was determined by UV using a JASCO V-730 spectrophotometer. Samples were prepared according to the method described by Couto et al. [43] with some modifications. Briefly, around $50 \mathrm{mg}$ of microparticles were weighted and melt at $70{ }^{\circ} \mathrm{C}$ to release the curcumin. Then, $20 \mathrm{~mL}$ of ethanol were added at $70{ }^{\circ} \mathrm{C}$ and the temperature maintained for $10 \mathrm{~min}$ to dissolve the curcumin. After cooling, the lipids precipitated and the sample was filtered using a syringe filter, (CHROMAFIL PTFE (45/25); $25 \mathrm{~mm}$ of diameter and $0.45 \mu \mathrm{m}$ pore size). The samples were analysed at $25{ }^{\circ} \mathrm{C}$ and a wavelength of $421 \mathrm{~nm}$ using ethanol as solvent medium. The concentration of the curcumin was calculated based on a calibration curve prepared from curcumin standard solutions in the range $0.001-0.01 \mathrm{mg} / \mathrm{mL} \quad(\mathrm{A}=206,79 \mathrm{C}+0,0859$; $\mathrm{R}^{2}=0.9938$ where $A$ is the absorbance at $421 \mathrm{~nm}$ and $C$ the curcumin concentration $(\mathrm{mg} / \mathrm{mL}))$. The control microparticles were also subjected to the same treatment to assure the noninterference of the lipid materials in the UV measurements. The encapsulation efficiency and load capacity were calculated according to the Eqs. (2) and (3), respectively.

Encapsulationefficiency $(E E, \%)=\frac{M_{\text {exp curcumin }}}{M_{\text {theoreticalcurcumin }}} \cdot 100$

$\operatorname{Loadcapacity}(L C, \%)=\frac{M_{\text {expcurcumin }}}{M_{\text {microparticles }}} \cdot 100$

Where $\mathrm{M}_{\text {exp curcumin }}$ was the mass of curcumin determined by $\mathrm{UV}, \mathrm{M}_{\text {theoretical curcumin }}$ the theoretical mass of curcumin in the weighted sample according to the used formulation, and $\mathrm{M}_{\text {microparticles }}$ the mass of the weighted microparticles." 


\section{Results and discussion}

\subsection{Experimental design}

Table 1 presents the runs defined in the experimental design, and expressed according to the three defined variables, namely the composition in terms of weight fraction and weight of the pseudo components, as well as the response results, i.e. the solidification temperature obtained for the defined ternary mixtures..

The predicted equation model is presented in Eq. (4), and the ANOVA analysis for the experimental model presented in Table 2. The obtained results showed a $\mathrm{p}$ (ANOVA) value of $0.000024\left(\mathrm{R}^{2}\right.$ of 0.95271 and $R_{a d j}^{2}$ of 0.92906 ) and p-value of 0.0716 , indicating that the model did not present lack of fit. It was observed that the interactions between beeswax and carnauba wax variables did not result significant $(p>0.05)$, being removed from the model. However, the ternary interaction between the beeswax, carnauba wax and miglyol variables, also considered no significant $(p>0.05)$, was maintained in the model since its removal would diminish the predictive capability of the model, as well as, leading to the reduction from special cubic to a quadratic model.

$T_{S}=48.5320 \mathrm{X}_{\mathrm{BW}}+55.6592 \mathrm{X}_{\mathrm{CW}}+49.0465 \mathrm{X}_{\mathrm{M}}-8.8846 \mathrm{X}_{\mathrm{BW}} \mathrm{X}_{\mathrm{M}}-17.8307 \mathrm{X}_{\mathrm{CW}} \mathrm{X}_{\mathrm{M}}$

The response surface obtained from the model equation is represented in Fig. 1. It can be noted that the miglyol weight fraction significantly influenced the behaviour of the mixtures. The interaction of miglyol with the corresponding beeswax and carnauba wax, i.e. $\mathrm{X}_{\mathrm{BW}}-\mathrm{X}_{\mathrm{M}}$ and $\mathrm{X}_{\mathrm{CW}}-\mathrm{X}_{\mathrm{M}}$ interactions, led to lower solidification temperatures. Considering that miglyol holds the lowest melting temperature among the three used components, namely a value of $-6.5^{\circ} \mathrm{C}$ [44], the highest its content in the mixture, the lower was the response (solidification temperature).

\subsection{Experimental model validation}

The experimental validation of the model was carried out by analysing three independent mixtures (V1, V2 and V3), selected based on the defined model. The mixture composition, the experimental Ts values, and the predicted confidence intervals are included in Table 3. As well, the validation points were depicted in the response surface showed in Fig. 1.
$\mathrm{V} 1$ and $\mathrm{V} 2$, mixtures having the same composition of points 1 and 3 (Table 1 ), respectively, resulted in slight different values for the experimentally determined $\mathrm{T}_{\mathrm{S}}$. Nevertheless, comparing the experimental values with the predicted intervals, it should be highlighted that V1 and V2 samples fulfilled the predicted theoretical confidence interval obtained from the used model, and are thus valid points. Concerning V3 sample, although the Ts value remained outside of the corresponding interval, the difference was minimum (lower than $1^{\circ} \mathrm{C}$ ) which may be acceptable in most practical applications. In conclusion, the results showed the suitability of the model as a prediction tool to estimate the solidification temperature of mixtures composed by beeswax, carnauba wax and miglyol. It is worth noting that the possibility to obtain particles of diverse composition but with similar melting temperatures is an advantage from a technological point of view, meaning that composition can be varied without appreciable change in melting behaviour and thus in processing conditions. This offers the possibility of changing the composition according to the application needs without modifying the process.

\subsection{Microparticles characterisation}

The lipid mixtures selected for the validation of the experimental design model, as described in Section 3.2., namely V1, V2 and V3 were further employed in the preparation of microparticles by spray congealing technology. For each composition, a series of control microparticles (without curcumin) and curcumin-loaded microparticles were prepared. Moreover, physical mixtures were also prepared for comparison purposes. The type of sample, codification and composition of the samples are summarised in Table 4.

The visual appearance of the produced curcumin-loaded microparticles and curcumin itself is shown in Fig. 2, where it can be observed the yellow hue for all microparticle systems, typical colour conferred by the curcumin compound.

Considering the differences of the microparticle's colour perception, their colour parameters were evaluated by colourimetric analysis and the results, as well as the colour equivalence, shown in Table 5. Colourimetric parameters were referred to as CIE-Lab coordinates, associated with a different characteristic of the samples. The $\mathrm{L}^{*}$ value is related to the lightness of the sample (in the range from black to white), $a^{*}$ value is associated to the rednessgreenness chromatography index and $b^{*}$ attributed to the yellowness-blueness axis colour index [45].

Table 1

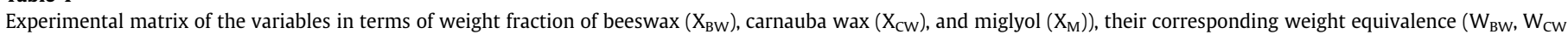
and $\mathrm{W}_{\mathrm{M}}$ ) and the solidification temperature (Ts) response.

\begin{tabular}{|c|c|c|c|c|c|c|c|}
\hline \multirow[t]{3}{*}{ Experimental run } & \multicolumn{6}{|c|}{ Variables } & \multirow{3}{*}{$\begin{array}{l}\text { Response } \\
\mathbf{T}_{\mathbf{S}}\left({ }^{\circ} \mathbf{C}\right)\end{array}$} \\
\hline & \multicolumn{3}{|c|}{$\begin{array}{c}\text { Weight fraction of pseudo components ( } g / \\
\mathrm{g}_{\text {total }} \text { ) }\end{array}$} & \multicolumn{3}{|c|}{ Weight of pseudo components (g) } & \\
\hline & $\mathbf{X}_{\mathbf{B W}}$ & $\mathbf{X}_{\mathbf{C w}}$ & $\mathbf{X}_{\mathbf{M}}$ & $\mathbf{W}_{\mathbf{B W}}{ }^{\mathrm{a}}$ & $\mathbf{w}_{\mathbf{c w}}{ }^{\mathrm{b}}$ & $\mathbf{W}_{\mathbf{M}}{ }^{\mathrm{c}}$ & \\
\hline 1 & 1.000 & 0.000 & 0.000 & 1.000 & 0.000 & 0.000 & 48.4 \\
\hline 2 & 0.000 & 1.000 & 0.000 & 0.400 & 0.600 & 0.000 & 55.1 \\
\hline 3 & 0.000 & 0.000 & 1.000 & 0.400 & 0.000 & 0.600 & 49.4 \\
\hline 4 & 0.500 & 0.500 & 0.000 & 0.700 & 0.300 & 0.000 & 52.5 \\
\hline 5 & 0.500 & 0.000 & 0.500 & 0.700 & 0.000 & 0.300 & 46.5 \\
\hline 6 & 0.000 & 0.500 & 0.500 & 0.400 & 0.300 & 0.300 & 47.4 \\
\hline 7 & 0.667 & 0.167 & 0.167 & 0.800 & 0.100 & 0.100 & 47.5 \\
\hline 8 & 0.167 & 0.667 & 0.167 & 0.500 & 0.400 & 0.100 & 51.6 \\
\hline 9 & 0.167 & 0.167 & 0.667 & 0.500 & 0.100 & 0.100 & 46.2 \\
\hline 10 & 0.333 & 0.333 & 0.333 & 0.600 & 0.200 & 0.200 & 48.1 \\
\hline 11 & 0.333 & 0.333 & 0.333 & 0.600 & 0.200 & 0.200 & 48.7 \\
\hline 12 & 0.333 & 0.333 & 0.333 & 0.600 & 0.200 & 0.200 & 48.8 \\
\hline 13 & 0.333 & 0.333 & 0.333 & 0.600 & 0.200 & 0.200 & 48.6 \\
\hline
\end{tabular}

\footnotetext{
${ }^{\text {a }} \mathrm{W}_{\mathrm{BW}}=0.6 \cdot \mathrm{X}_{\mathrm{BW}}+0.4$.

b $\mathrm{W}_{\mathrm{CW}}=0.6 \cdot \mathrm{X}_{\mathrm{CW}}$.

c $\mathrm{W}_{\mathrm{M}}=0.6 \cdot \mathrm{X}_{\mathrm{M}}$.
} 
Table 2

Results of the simplex centroid design 3-factor mixture for the solidification temperature.

\begin{tabular}{|c|c|c|c|c|c|}
\hline & Sum of squares & Degrees of freedom & Mean square & $\mathrm{F}$ & p-value \\
\hline Model & 72.8725 & 4 & 18.21831 & 40.28904 & 0.000024 \\
\hline Total Error & 3.61752 & 8 & 0.45219 & - & - \\
\hline Lack of Fit & 3.32752 & 5 & 0.66550 & 6.88453 & - \\
\hline Pure Error & 0.29000 & 3 & 0.09667 & - & 0.071586 \\
\hline Total Adjusted & 76.49077 & 12 & 6.37423 & - & - \\
\hline
\end{tabular}

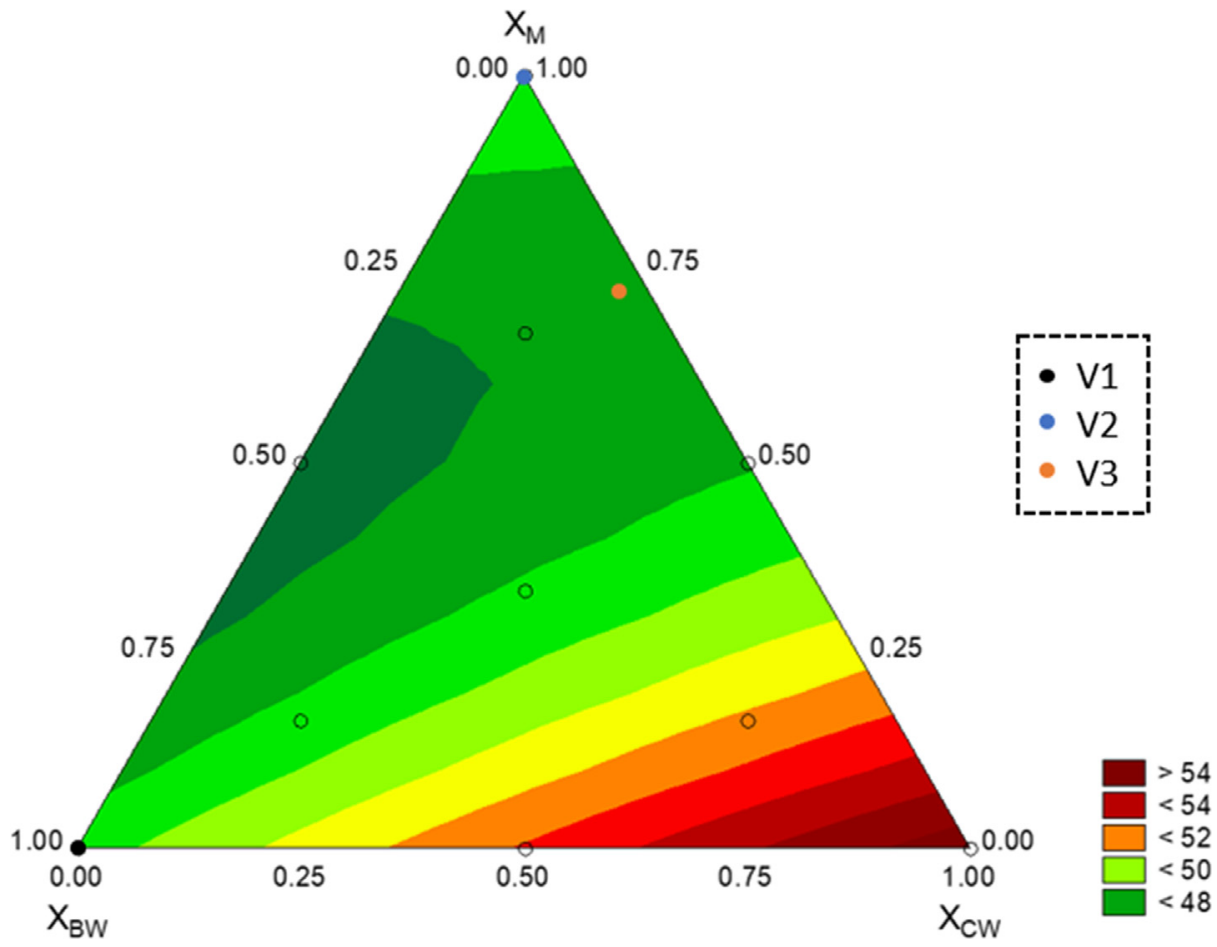

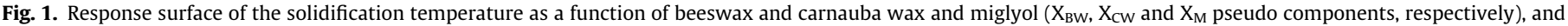
V1, V2 and V3 validation points.

Table 3

Lipid mixtures composition (weight fraction and weight) and Ts experimental values and predicted intervals (95\% of confidence).

\begin{tabular}{|c|c|c|c|c|c|c|c|c|}
\hline \multirow[t]{2}{*}{ Sample } & \multicolumn{3}{|c|}{$\begin{array}{l}\text { Weight fraction of } \\
\text { pseudocomponents }\left(\mathrm{g} / \mathrm{g}_{\text {total }}\right)\end{array}$} & \multicolumn{3}{|c|}{ Weight of pseudocomponents (g) } & \multirow[t]{2}{*}{ ExperimentalT $_{S}\left({ }^{\circ} \mathrm{C}\right)$} & \multirow[t]{2}{*}{ Predicted interval $(95 \%) \mathrm{T}_{\mathrm{S}}\left({ }^{\circ} \mathrm{C}\right)$} \\
\hline & $\mathbf{X}_{\mathbf{B W}}$ & $\mathbf{X}_{\mathbf{C W}}$ & $\mathbf{X}_{\mathbf{M}}$ & $\mathbf{W}_{\mathbf{B W}^{\mathrm{a}}}$ & $\mathbf{W}_{\mathbf{c w}}{ }^{\mathrm{b}}$ & $\mathbf{W}_{\mathbf{M}}{ }^{\mathrm{c}}$ & & \\
\hline V1 & 1.000 & 0.000 & 0.000 & 1.000 & 0.000 & 0.000 & 46.5 & $46.5 \leq 48.5 \leq 50.6$ \\
\hline V2 & 0.000 & 0.000 & 1.000 & 0.400 & 0.000 & 0.600 & 50.5 & $46.9 \leq 49.0 \leq 51.2$ \\
\hline V3 & 0.030 & 0.250 & 0.720 & 0.418 & 0.150 & 0.432 & 44.5 & $45.4 \leq 47.3 \leq 49.1$ \\
\hline
\end{tabular}

a $\mathrm{W}_{\mathrm{BW}}=0.6 \cdot \mathrm{X}_{\mathrm{BW}}+0.4$

b $\mathrm{W}_{\mathrm{CW}}=0.6 \cdot \mathrm{X}_{\mathrm{CW}}$.

c $\mathrm{W}_{\mathrm{M}}=0.6 \cdot \mathrm{X}_{\mathrm{M}}$.

It was observed that microparticles led to colour parameters not substantially different, yielding values around 68-72, 5-10 and 53-65 for $\mathrm{L}^{*}, \mathrm{a}^{*}$ and $\mathrm{b}^{*}$ coordinates, respectively; and observed differences were related to the lipid mixtures. MP1 sample, namely microparticles composed just by beeswax resulted in the lowest $a^{*}$ and $b^{*}$ values, that is, they presented the lowest redness and yellowness values. The incorporation of miglyol (MP2) led to a slight reduction in the lightness of the microparticles, comparatively with MP1 sample. In contrast, a more perceptible variation in $\mathrm{a}^{*}$ and $b^{*}$ values was observed, towards more red and yellow coordinates, as can be perceived in the appearance of microparticles shown in Fig. 2. The analogous redness and yellowness effect was observed in MP3 microparticles, being the effect slightly lower probably due to the lower miglyol content (comparing with MP2). Moreover, the incorporation of carnauba wax in the MP3 sample, increased the lightness of the microparticles, in comparison with beeswax-based samples, as it was also reported in other works [46].

The morphology of the curcumin loaded microparticles $(1.5 \% \mathrm{w} /$ w) was analysed by SEM, and the images are shown in Fig. 3. The microparticles presented the typical spherical morphology of the solid lipid microparticles $[47,48]$ evidencing the suitability of the spray congealing approach for their production. Moreover, the existence of microparticle's clusters was also observed in the formulations, as reported in previous works dealing with spray congealing process $[49,50]$. This phenomenon was attributed due to 
Table 4

Type of sample, codification and composition of the samples.

\begin{tabular}{llll}
\hline Type of sample & Codification & $\begin{array}{l}\text { Mass fraction of } \\
\text { encapsulants } \mathrm{X}_{\mathrm{BW}} / \mathrm{X}_{\mathrm{CW}} / \mathrm{X}_{\mathrm{M}}\end{array}$ & $\begin{array}{l}\text { Curcumin } \\
(\% \mathrm{w} / \mathrm{w})\end{array}$ \\
\hline Control microparticles & CMP1 & $1 / 0 / 0$ & - \\
& CMP2 & $0.4 / 0 / 0.6$ & - \\
\multirow{5}{*}{ Loaded microparticles } & CMP3 & $0.418 / 0.15 / 0.432$ & - \\
& MP1 & $1 / 0 / 0$ & 1.5 \\
& MP2 & $0.4 / 0 / 0.6$ & 1.5 \\
Physical mixtures & MP3 & $0.418 / 0.15 / 0.432$ & 1.5 \\
& PM1 & $1 / 0 / 0$ & 1.5 \\
& PM2 & $0.4 / 0 / 0.6$ & 1.5 \\
& PM3 & $0.418 / 0.15 / 0.432$ & 1.5 \\
\hline
\end{tabular}

the fact that microparticles might not be wholly solidified during the time-frame of the productive process. Generally, it is known that the melting temperature of the constituents ranges from 62 to 64 , from 82 to 86 and from -6.5 to $-2{ }^{\circ} \mathrm{C}$ for the beeswax, carnauba wax and miglyol, respectively. These values supported the effect, that resulted more significant in the case of MP2 microparticles (Fig. 3b), the formulation composed by beeswax and miglyol, namely the lipids holding the lowest melting temperatures. In the case of MP3 sample (Fig. 3c), the incorporation of carnauba wax to the mixture composition (lipid mixture with the highest melting temperature) lead to the reduction of the clustering effect, comparing with MP2. A similar behaviour was reported by Albertini and co-workers [51].

The particle size distribution of the curcumin loaded microparticles $(1.5 \% \mathrm{w} / \mathrm{w})$, as well as the respective control microparticles,
Table 5

$L^{*}, a^{*}$ and $b^{*}$ colour values of the curcumin-loaded microparticles.

\begin{tabular}{ccccc}
\hline Sample & $\mathbf{L}^{*}$ & $\mathbf{a}^{*}$ & $\mathbf{b}^{*}$ & Colour \\
\hline MP1 & $69.52 \pm 0.92$ & $5.39 \pm 1.18$ & $53.86 \pm 1.60$ & \\
\hline MP2 & $68.69 \pm 0.38$ & $9.54 \pm 0.45$ & $64.91 \pm 4.43$ & \\
\hline MP3 & $71.79 \pm 1.48$ & $9.43 \pm 1.24$ & $64.00 \pm 2.48$ & \\
\hline
\end{tabular}

namely their counterparts with no curcumin, are shown in Fig. 4. The particle sizes referred to the maximum at 10,50 and $90 \%$ of the microparticles in volume are shown in Table 6.

In general, the microparticles presented a volume size distribution ranging from 0.1940 to $139 \mu \mathrm{m}$, availing their micro-scale. Other reported works, namely the one carried out by Consoli and co-workers [49], in which the encapsulation of gallic acid by several material compositions was evaluated, pointed out that the formulation holding the highest amount of fully hydrogenated soybean oil favoured the decrease of the average volume sizes, fact supported by its solid state at room temperature. Similarly, the physical state of the mixture components could be related with the particle size and observed distribution variations. It was observed that the MP1 sample showed, in general, similar particle size distribution comparing to CMP1 counterpart, highlighting the solid-state of the mixture components at room temperature. Appositively, the presence of miglyol (liquid at room temperature) in MP2 and MP3 samples, broadened the particle size distribution, which was also shifted to higher values, in respect to the control
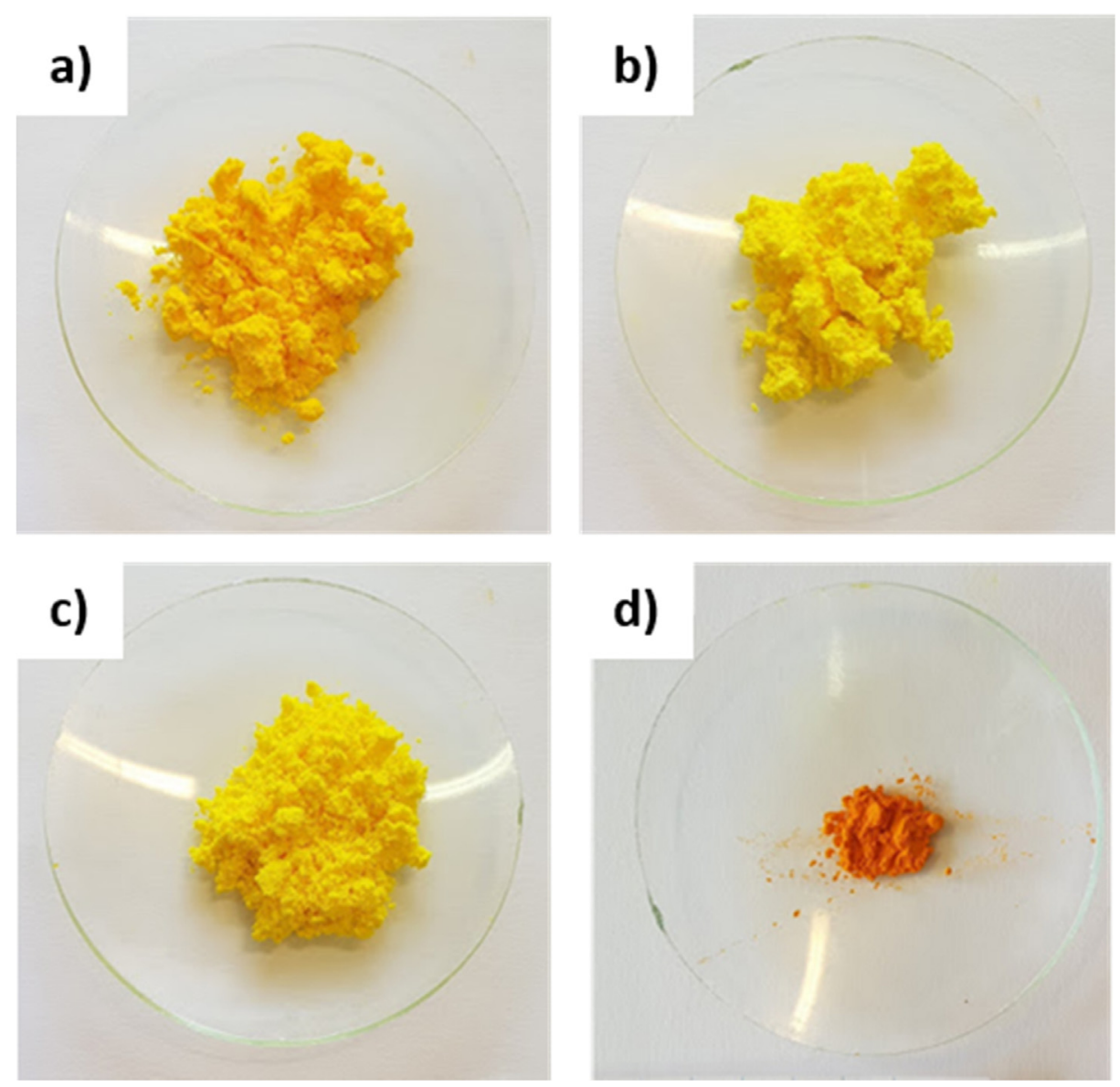

Fig. 2. Images of curcumin loaded a) MP1, b) MP2 and c) MP3 microparticles and d) curcumin. 
a)
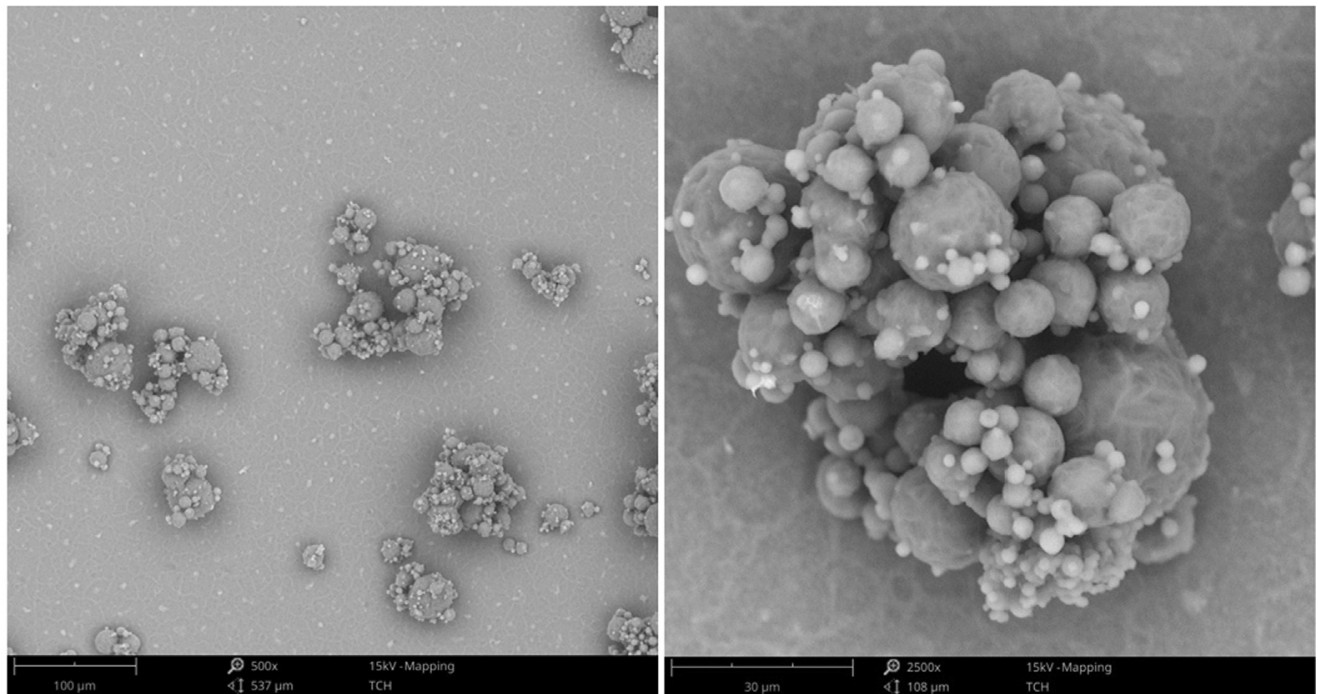

b)
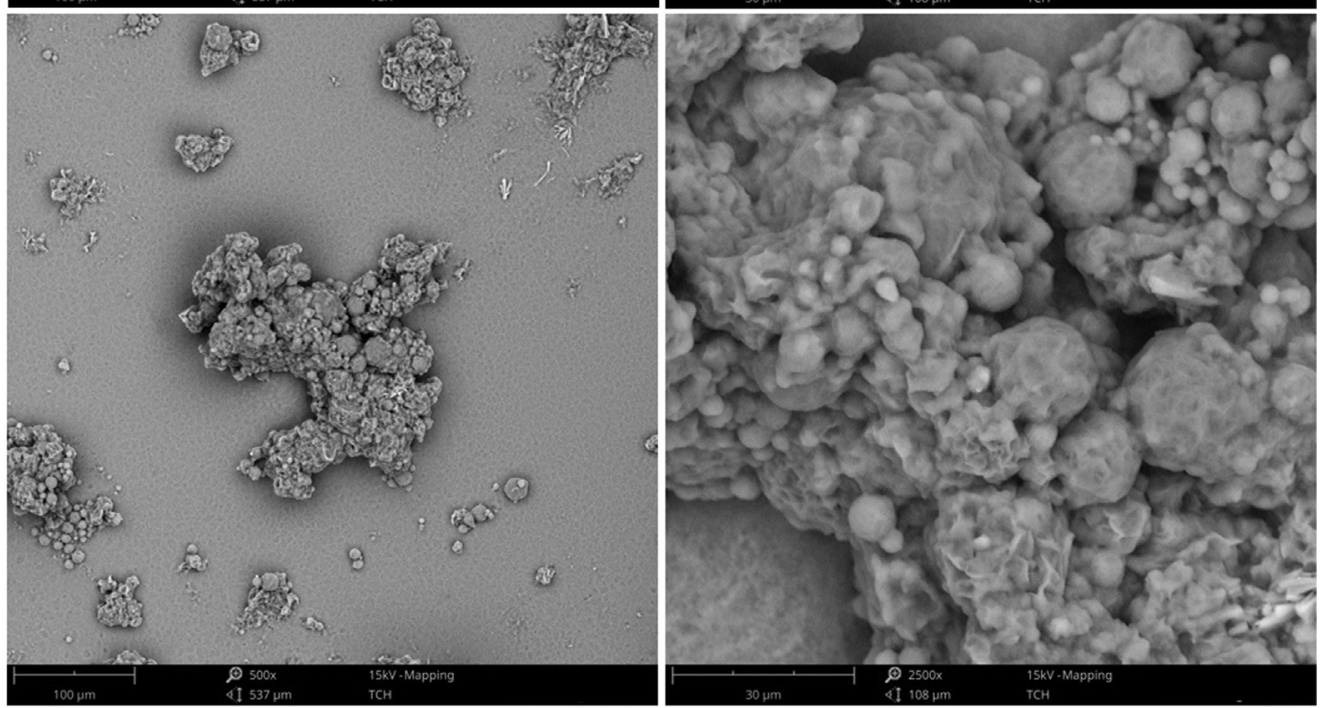

c)
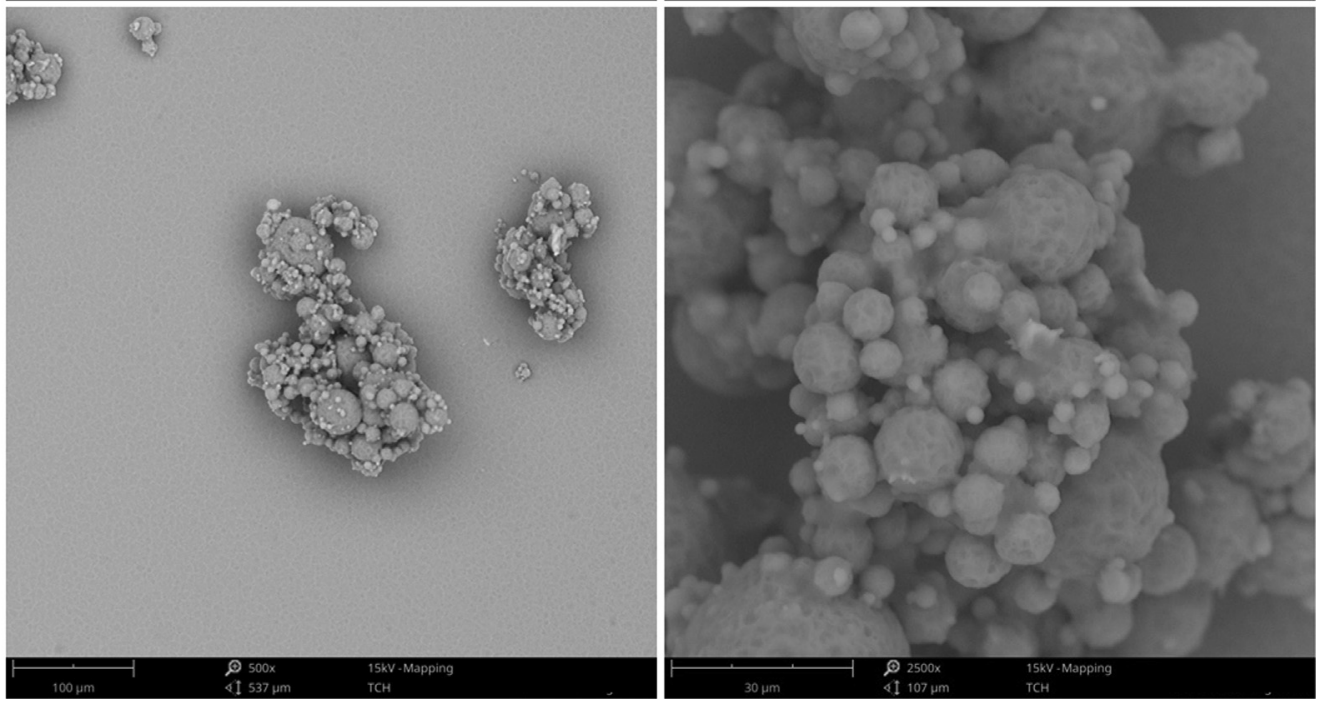

Fig. 3. SEM images of the curcumin loaded a) MP1, b) MP2 and c) MP3 at 500x (on the left) and 2500x (on the right).

microparticles (CMP2 and CMP3). This fact could be related with the higher flexibility (mobility freedom) of miglyol. The effect was less significant in the MP3 sample, considering the lower miglyol content in the mixture as well as the presence of carnauba wax, the component presenting the highest melting temperature range, and thereby, favouring the control of microparticle's struc- 

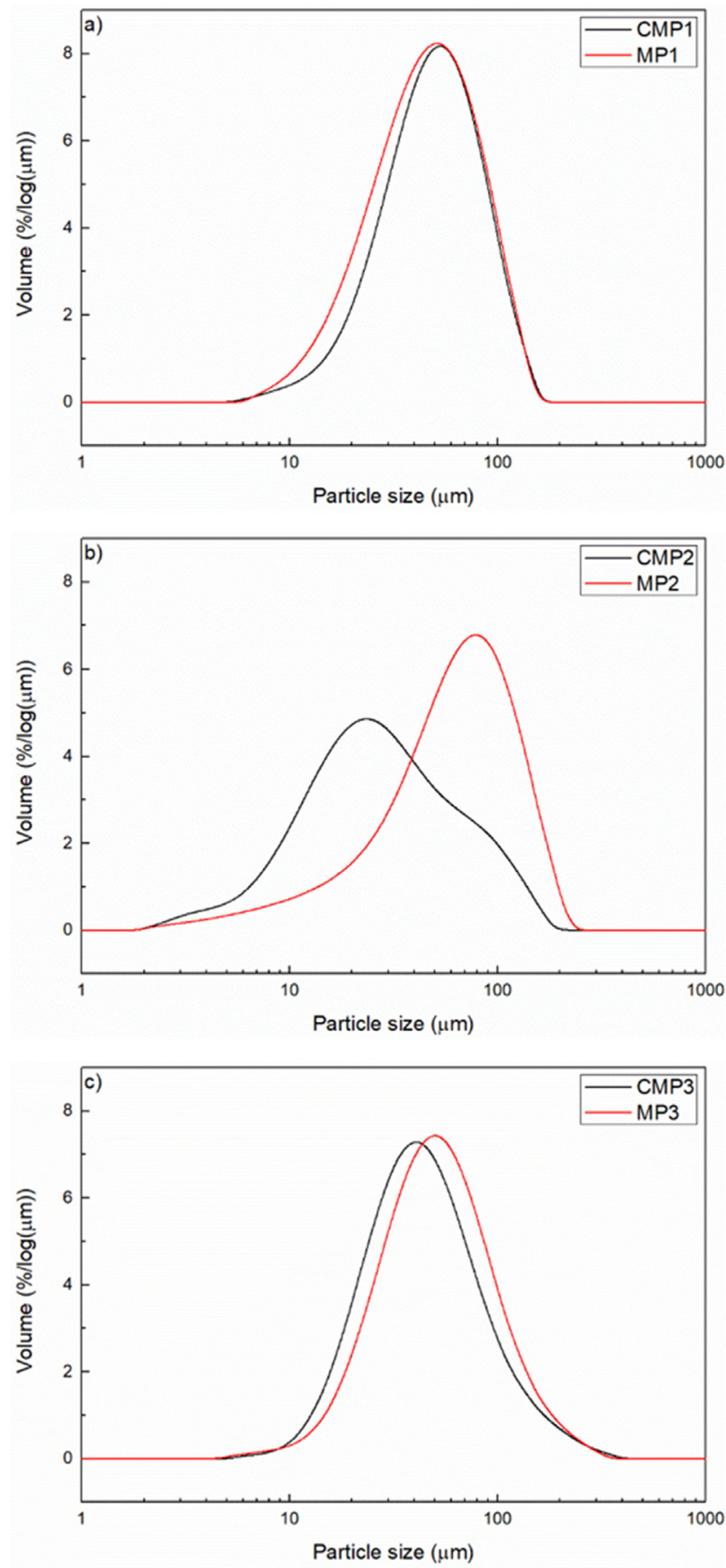

Fig. 4. Particle size distribution in volume of the control and respective curcumin loaded microparticles: a) CMP1 and MP1, b) CMP2 and MP2 and c) CMP3 and MP3.

Table 6

Particle size of the samples for the $10 \%\left(D_{10}\right), 50 \%\left(D_{50}\right)$ and $90 \%\left(D_{90}\right)$ of the measured microparticles in volume.

\begin{tabular}{llll}
\hline Sample & $\mathrm{D}_{10}(\mathrm{~lm})$ & $\mathrm{D}_{50}(\mathrm{Im})$ & $\mathrm{D}_{90}(\mathrm{~lm})$ \\
\hline CMP1 & $0.48 \pm 0.01$ & $47.80 \pm 0.20$ & $95.60 \pm 0.90$ \\
MP1 & $8.48 \pm 3.40$ & $45.00 \pm 3.00$ & $95.00 \pm 3.00$ \\
CMP2 & $0.19 \pm 0.01$ & $21.30 \pm 0.20$ & $79.00 \pm 2.00$ \\
MP2 & $0.41 \pm 0.01$ & $60.20 \pm 0.50$ & $139.00 \pm 4.00$ \\
CMP3 & $9.16 \pm 0.09$ & $41.60 \pm 0.30$ & $103.00 \pm 2.00$ \\
MP3 & $11.60 \pm 0.09$ & $49.40 \pm 0.50$ & $117.00 \pm 3.00$ \\
\hline
\end{tabular}

ture when curcumin is incorporated. Nevertheless, it has been reported in the literature that other parameters, including the viscosity of the melted mixture had influence in the spray congealing atomisation process (an effect also conditioned by component's intrinsic properties), namely in the particle size of the obtained particles [39,40]. For example, Albertini et al. [39], revealed the tendency to reach higher average particle size values when the viscosity of the mixture was increased. By contrast, Matos-Jr et al. [52] reported that at high atomisation working pressures, namely 4 bar, high viscosity fluids favour the nebulization process, leading to smaller particle sizes.

Mixture components (beeswax, carnauba wax, miglyol and curcumin), control and curcumin-loaded microparticles, and the physical mixtures were analysed by FTIR, and the chemical structural features are evidenced in the spectra shown in Fig. 5.

In general, the constituents showed the typical bands attributed to their corresponding functional groups. Curcumin spectrum presented a band at $3510 \mathrm{~cm}^{-1}$ attributed to the stretching vibration of hydroxyl $(-\mathrm{OH})$ free groups and intense bands at 1640,1647 and $1650 \mathrm{~cm}^{-1}$ related to the vibration of carbonyl groups. The bands in the region between 1380 and $1470 \mathrm{~cm}^{-1}$ were associated to the $\mathrm{C}=\mathrm{C}$ stretching vibrations of the aromatic ring, and the elongation of C-O groups, while the bands from 1155 to $1020 \mathrm{~cm}^{-1}$ were assigned to the stretching vibration of the ether (C-O) groups, and the ones located at $900-700 \mathrm{~cm}^{-1}$ related to the $\mathrm{C}-\mathrm{H}$ of the alkene groups [53].

Beeswax spectrum presented the typical bands around $2957 \mathrm{~cm}^{-1}$ associated with asymmetric stretching vibration of $\mathrm{CH}_{3}$ and asymmetric and symmetric stretching vibration of $\mathrm{CH}_{2}$ around 2922 and $2852 \mathrm{~cm}^{-1}$, respectively. Also, $\mathrm{CH}_{2}$ scissor deformation and rocking vibration of $\mathrm{CH}_{2}$ groups were appreciated around 1456 and $720 \mathrm{~cm}^{-1}$ [54]. The carbonyl $\mathrm{C}=0$ stretching vibrations were observed around 1739 and $1172 \mathrm{~cm}^{-1}$ overlapped with the $\mathrm{C}-\mathrm{H}$ bending vibrations in the band about $1172 \mathrm{~cm}^{-1}$, characteristic of the monosaturated fatty acid esters of the beeswax $[54,55]$. Similar bands to that showed by beeswax were observed in the carnauba wax spectrum [46,56]. Miglyol spectrum showed bands around 2956, 2926 and $2855 \mathrm{~cm}^{-1}$ related to the C$\mathrm{H}$ asymmetrical and symmetrical stretching vibrations of $\mathrm{CH}_{3}$ and $\mathrm{CH}_{2}$ groups, whereas $\mathrm{C}-\mathrm{H}$ bending vibration of $\mathrm{CH}_{2}$ groups was assigned at 1465 and $1378 \mathrm{~cm}^{-1}$ and $720 \mathrm{~cm}^{-1}$ their in-plane rocking vibration. A strong band about $1743 \mathrm{~cm}^{-1}$ reflected the ester $\mathrm{C}=\mathrm{O}$ groups of the triglycerides while the bands located at 1230 , 1170 and $1064 \mathrm{~cm}^{-1}$ were associated to the $\mathrm{C}-\mathrm{O}$ stretching vibrations, but specifically at $1108 \mathrm{~cm}^{-1}$, where the stretching vibration associated to the $\mathrm{C}-\mathrm{O}$ of ester groups was observed [57].

FTIR spectra of curcumin loaded microparticles (MP1, MP2 and MP3) showed the aforementioned $\mathrm{C}-\mathrm{H}$ symmetric and asymmetric stretching vibration bands corresponding to the $\mathrm{CH}_{3}$ and $\mathrm{CH}_{2}$ groups of the lipids in the range between 3000 and $2800 \mathrm{~cm}^{-1}$, the stretching vibration band of $\mathrm{C}=\mathrm{O}$ groups at $1750 \mathrm{~cm}^{-1}, \mathrm{C}-\mathrm{O}$ of the ester groups around $1180 \mathrm{~cm}^{-1}$ and the in-plane rocking vibration of $\mathrm{CH}_{2}$ groups located at $720 \mathrm{~cm}^{-1}$ [10,58]. In MP2 and MP3 samples, the addition of miglyol led to less intense bands at $3000-2800 \mathrm{~cm}^{-1}$, related to the stretching vibrations of $\mathrm{CH}_{3}$ and $\mathrm{CH}_{2}$ groups [10,58] and angular deformation bands of $\mathrm{CH}_{2}$ groups around 1479-1380 $\mathrm{cm}^{-1}$ [57]. While the incorporation of miglyol resulted in an enhancement of $C=O$ stretching vibration band intensity at $1750 \mathrm{~cm}^{-1}$ in MP2, this effect was less perceptible in MP3 sample, influenced by the lower miglyol content and the addition of carnauba wax to the mixture.

Comparing curcumin-loaded microparticles with the corresponding controls, similar spectra were observed, whereas the analogous physical mixtures (containing curcumin), showed the characteristic band of curcumin around $3510 \mathrm{~cm}^{-1}$ (attributed to $-\mathrm{OH}$ free groups). This fact implied that the curcumin could result 

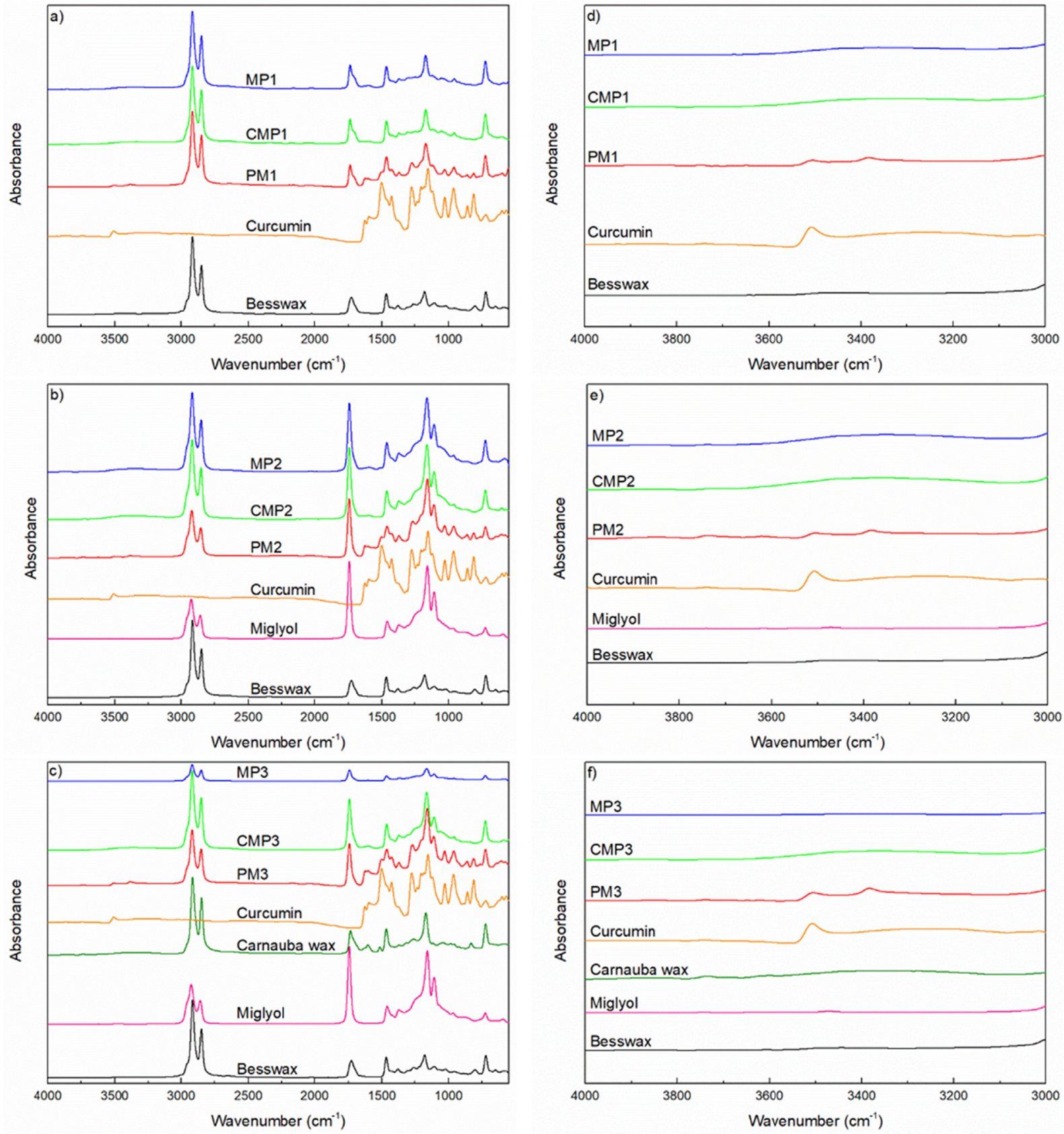

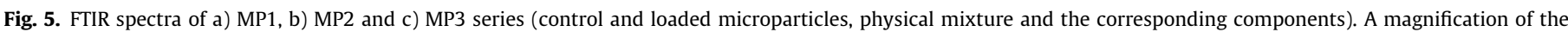
spectral range 4000 and $3000 \mathrm{~cm}^{-1}$ is also presented for d) MP1, e) MP2 and f) MP3 series.

embedded within the lipid matrices in the microparticles, which is considered an evidence of the efficient encapsulation approach [59-61].

The thermal behaviour of the constituents, namely carnauba wax, beeswax and curcumin, control microparticles and the corresponding curcumin-loaded microparticles were analysed by DSC, and the thermograms are shown in Fig. 6. The thermal properties, namely melting temperature $\left(\mathrm{T}_{\mathrm{m}}\right)$ and melting enthalpy $\left(\Delta \mathrm{H}_{\mathrm{m}}\right)$ obtained from the thermograms, are summarised in Table 7. For comparison, the behaviour of the physical mixtures was also analysed. Considering the liquid state of miglyol at room temperature, its thermogram was not included in the analysis.

The melting temperature of the constituents was corroborated with typical values reported in the literature, namely curcumin at $175.4{ }^{\circ} \mathrm{C}[19,62]$, beeswax at $68.4{ }^{\circ} \mathrm{C}[63]$ and carnauba wax at $86.8{ }^{\circ} \mathrm{C}$ [64]. It was observed that MP1 series which include CMP1, MP1 and PM1 showed the highest $\mathrm{T}_{\mathrm{m}}$ values (comparing with the other series), being close to that of beeswax, the only lipid present in the mixture composition. It should be worth noting that the incorporation of curcumin to MP1 microparticles led to a considerable increase of the melting enthalpy (from 149.5 to $167.6 \mathrm{~J} / \mathrm{g}$ ) suggesting that the curcumin could act as a nucleating agent favouring the arrangement capacity of the beeswax. Also, the absence of an endothermic peak around the melting temperature of the base curcumin evidenced the amorphous structure adopted by curcumin in the process.

The addition of miglyol (MP2 and MP3 series) reduced the $T_{m}$ of the control and curcumin-loaded microparticles (being the effect 

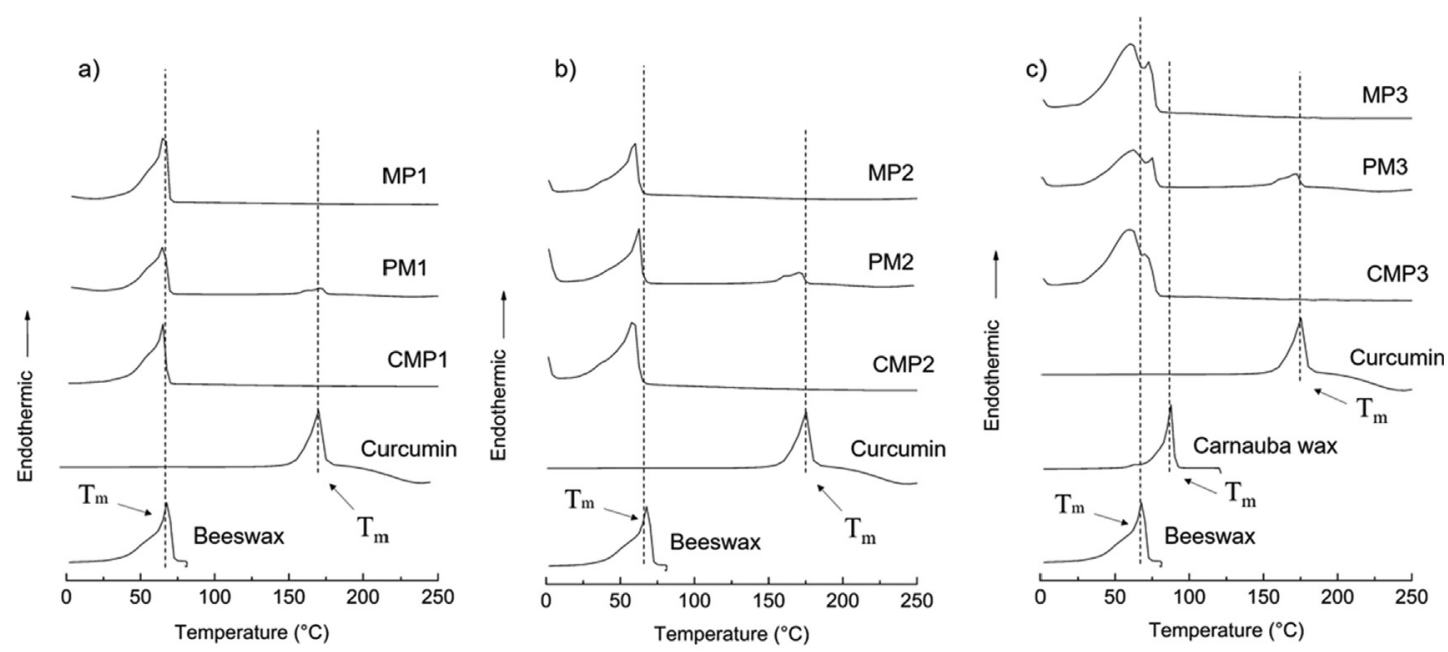

Fig. 6. DSC thermograms of a) MP1, b) MP2 and c) MP3 series (control and loaded microparticles, physical mixture and the corresponding constituents of the series).

Table 7

Melting temperature $\left(\mathrm{T}_{\mathrm{m}}\right)$ and melting enthalpy $\left(\Delta \mathrm{H}_{\mathrm{m}}\right)$ of the constituents, control and curcumin loaded microparticles and physical mixtures.

\begin{tabular}{|c|c|c|c|c|c|}
\hline Sample & Type of sample & $\mathrm{T}_{\mathrm{m}}\left({ }^{\circ} \mathrm{C}\right)$ & $\Delta \mathrm{H}_{\mathrm{m}}(\mathrm{J} / \mathrm{g})$ & $\mathrm{T}_{\mathrm{m} 2}\left({ }^{\circ} \mathrm{C}\right)$ & $\Delta \mathrm{H}_{\mathrm{m} 2}(\mathrm{~J} / \mathrm{g})$ \\
\hline Beeswax (BW) & Constituent & 68.4 & 158.8 & - & - \\
\hline Carnauba wax (CW) & & 86.8 & 173.1 & - & - \\
\hline Curcumin (C) & & 175.4 & 125.8 & - & - \\
\hline CMP1 & Control microparticles & 65.9 & 149.5 & - & - \\
\hline CMP2 & & 57.6 & 71.3 & - & - \\
\hline CMP3 & & 59.3 & 105.7 & - & - \\
\hline MP1 & Curcumin loaded microparticles & 66.4 & 167.6 & - & - \\
\hline MP2 & & 58.7 & 63.4 & - & - \\
\hline MP3 & & 60.4 & 93.7 & - & - \\
\hline PM1 & Physical mixture & 65.6 & 124.6 & 170.8 & 13.8 \\
\hline PM2 & & 62.0 & 55.0 & 171.2 & 11.8 \\
\hline PM3 & & 62.2 & 75.6 & 171.7 & 13.0 \\
\hline
\end{tabular}

slightly more noticeable in control samples) [13]. Comparing both MP2 and MP3 series with that of MP1, a reduction in the enthalpy values was observed, also associated with the ordering capacity hindrance provided by the miglyol to the system. Even so, the effect in MP3 series was reduced considering the lower miglyol content in the formulation, as well as the addition of carnauba wax, characterised by holding a high $\mathrm{T}_{\mathrm{m}}$ value (solid component at room temperature). Moreover, in the loaded microparticles (MP2 and MP3), even though curcumin showed to be analogous to the amorphous structure adopted in MP1 sample, in this case it did not promote an enthalpy increase for the loaded microparticles (comparing to the corresponding controls), but a slight increase was observed in $T_{m}$ values. This fact suggested the predominant effect of miglyol over the curcumin influence in these systems.

In general, the physical mixtures showed slightly higher $T_{m}$ values when compared with the corresponding microparticles (or similar in MP1 series), while $\Delta \mathrm{H}_{\mathrm{m}}$ values were reduced. By contrast, an endothermic peak about $170-172{ }^{\circ} \mathrm{C}$ was observed, attributed to the presence of curcumin crystalline domains. The absence of the aforementioned endothermic peak in the loaded microparticles evidenced the amorphous conformation of curcumin resulting in a homogeneous solid mixture with the lipids mixtures. The work reported by Ramalingam et al. [65] based on the encapsulation of curcumin in solid lipid nanoparticles composed by glycerol monostearate and palmitic acid obtained similar effects, resulting in an indicative parameter of the degree of miscibility between curcumin and the encapsulant material, as well as the entrapment of the curcumin within the solid lipid core. A similar effect was described by Behbahani et al. [66], where analogous results obtained by the encapsulation of curcumin in solid lipid particles (composed by stearic acid and tripalmitin) indicated the complete solubilisation of the curcumin within the lipid matrix.

The crystallinity of the solid constituents (beeswax, carnauba wax and curcumin), control and curcumin loaded microparticles were analysed by X-ray diffraction patterns, and the diffractograms are shown in Fig. 7.

Beeswax (BW) presented two typical intense crystalline peaks at $2 \theta=21.34^{\circ}$ and $23.65^{\circ}$ also reported in the literature [67-69], while carnauba wax diffractogram showed two peaks located at $2 \theta=21.6^{\circ}$ and $23.8^{\circ}$, associated to the crystalline regions of the lipid [70]. Similarly, control and curcumin-loaded microparticles presented two peaks around $2 \theta=21-21.5^{\circ}$ and $2 \theta=24^{\circ}$ corresponding to the crystalline peaks observed for the constituents, evidencing the crystalline structure arranged by the lipids in the microparticles structure.

Concerning samples CMP2 and CMP3, the peaks showed lower intensity comparing with CMP1, influenced by the addition of miglyol. The homologue peak position in the microparticles (that is, $2 \theta$ values), comparing with those of the constituents, indicated that the addition of miglyol did not affect the polymorphic arrangement of the lipids in the microparticles structure. By contrast, miglyol incorporation hindered the ordering ability of the beeswax evidenced by the peak intensity decrease $[41,44]$, as observed in DSC results (e.g. lower $\Delta H_{m}$ values were observed). 

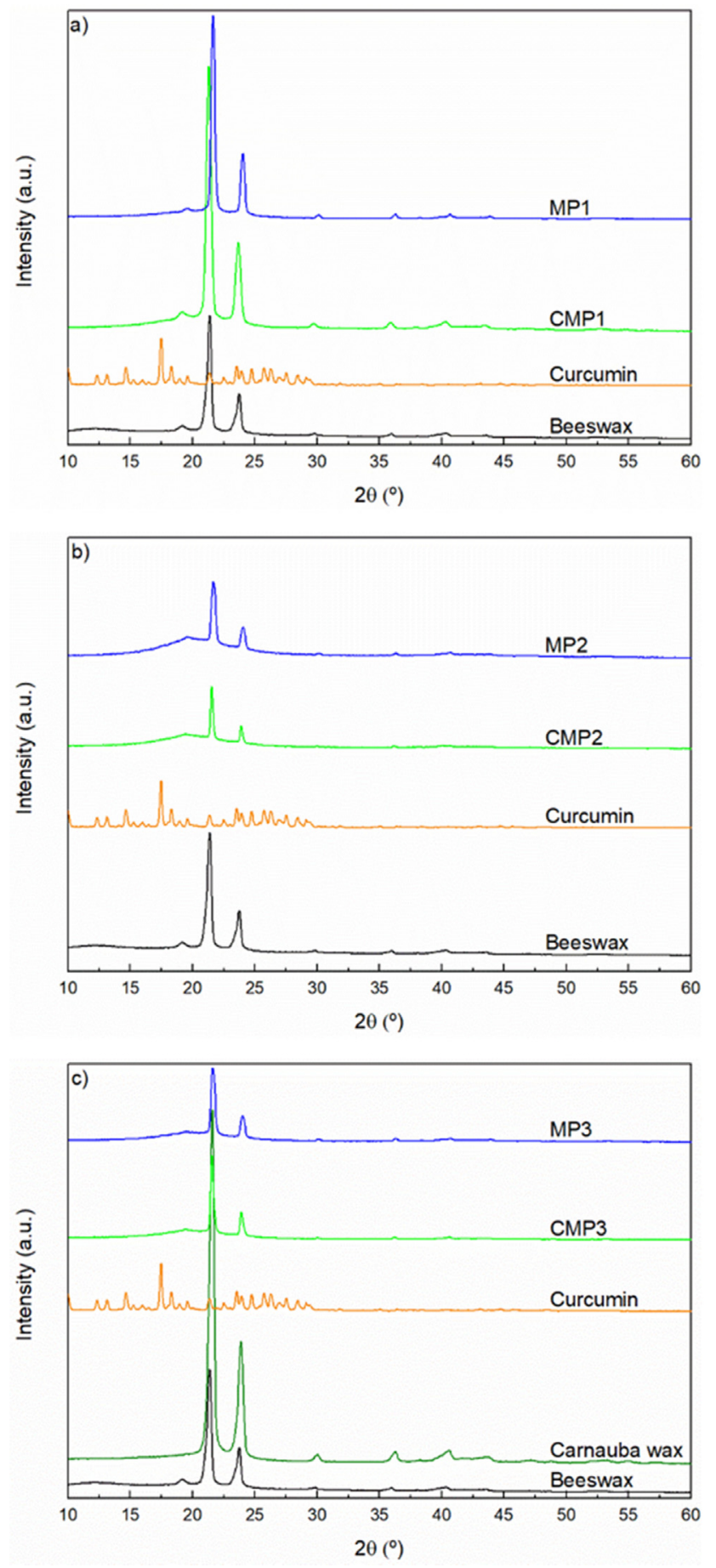

Fig. 7. X-Ray diffraction of a) MP1, b) MP2 and c) MP3 series (control and loaded microparticles and the corresponding solid constituents of the series).

The curcumin X-ray diffraction patterns showed several peaks indicative of the crystalline structure associated to its pure form [71]. By contrast, the absence of peaks related to curcumin crystalline domains in X-ray diffraction patterns in the loaded microparticles indicated that curcumin was dissolved in the lipid matrix [59,60], a fact also supported by DSC and FTIR results. Namely, the only samples evidencing a melting transition and absorption vibrations attributed to curcumin, respectively in DSC and FTIR, were the physical mixtures. In fact, when the microparticles were formed the presence of this compound was not observed, corroborating its amorphisation. These evidences were
Table 8

Encapsulation efficiency and load capacity of the curcumin-loaded microparticles.

\begin{tabular}{lll}
\hline Sample & EE (\%) & LC (\%) \\
\hline MP1 & 44.72 & 0.67 \\
MP2 & 77.51 & 1.16 \\
MP3 & 85.20 & 1.28 \\
\hline
\end{tabular}

in accordance with reported data that pointed out that the preparation of particles, or alternative curcumin-based polymeric systems, can induce the phase change of the incorporated compound due to its entrapment in the matrix [72,73]. In fact, the dispersion of curcumin into the polymer matrix usually inhibits its ordering ability, turning its crystalline structure into an amorphous state [74]. Moreover, other works emphasize the advantages of this phase transition, including the enhanced potential for sustained release of compounds [75].

The encapsulation efficiency and the load capacity were determined by UV spectroscopy and the results are summarized in Table 8. It was observed that EE varied according to the particle's composition, ranging from 45 to $85 \%$. This observation is in accordance with other reported results that indicated several aspects influencing $\mathrm{EE}$, including the used formulation, i.e., the composition influenced the affinity between the encapsulating material and the encapsulated agent, in this case between the lipid mixture and curcumin [76,77]. In particular, it is known that systems holding higher crystallization ability can difficult the incorporation of the active compounds into the particles [77]. Taking into consideration the observed thermal behaviour of the lipid mixtures, namely by analysing the control particles (CMP1, CMP2, and CMP3), it was observed that CMP1 showed the highest crystallization ability in comparison to CMP2 and CMP3, fact corroborated by the higher $\Delta \mathrm{H}_{\mathrm{m}}$. This fact can justify the lower encapsulation efficiency of the MP1 system, which showed also a higher $\Delta \mathrm{H}_{\mathrm{m}}$ comparatively with the corresponding control (CMP1) meaning that MP1 not only showed an enhanced ordering ability, but this effect was strengthened by the curcumin incorporation. For the other systems (MP2 and MP3) the opposite effect was observed, namely a decrease of $\Delta \mathrm{H}_{\mathrm{m}}$ was registered in comparison with the respective controls (CMP2 and CMP3). These observations are also corroborated by the XRD results, where more intense crystallization peaks associated to the encapsulated materials were observed for both CMP1 and MP1 series.

\section{Conclusions}

In this work, a systematic study addressing the use of lipid mixtures to modulate the solidification temperature in spray congealing applications was carried out. Initially, the optimisation of the lipid mixture composition (beeswax, carnauba wax and miglyol) was analysed by a simplex-centroid experimental design adjusted to a special cubic model, according to their solidification temperature (essential parameter for the suitable preparation of microparticles by the spray congealing process). After the definition of the effective working window, three different formulations were prepared for the validation of the designed model as well as for the preparation of the microparticles, here tested with curcumin. The optimised spray congealing strategy led to 3 microparticles series (controls and curcumin loaded samples) holding spherical shape in the micrometric scale, as revealed by SEM and particle analyses results, respectively. In general, the effective incorporation of curcumin in the microparticles was corroborated by FTIR, DSC and XRD results revealed that the curcumin structure was modified from crystalline to amorphous enabling its dissolution into the lipid 
mixtures. Nevertheless, the encapsulation efficiency was dependent from the matrix composition and properties, in particular matrices with higher ability to crystalize were less effective to retain and encapsulate the curcumin.

\section{Declaration of Competing Interest}

The authors declare that they have no known competing financial interests or personal relationships that could have appeared to influence the work reported in this paper.

\section{Acknowledgements}

This work was financially supported by: CIMO (UIDB/00690/2020), and Associate Laboratory LSRE-LCM (UIDB/50020/2020) funded by national funds through FCT/MCTES (PIDDAC), and European Regional Development Fund (ERDF) through the Regional Operational Program North 2020, within the scope of Project Mobilizador Norte-01-0247-FEDER-024479 (ValorNatural). FCT, PI, through the institutional scientific employment program-contract for I.P. Fernandes contract through the celebration of program-contract foreseen in No. 4, 5 and 6 of article $23^{\circ}$ of Decree-Law No. 57/2016, of 29th August, amended by Law No. 57/2017, of 19th July; and Valor Natural project for the contract of A. Santamaria-Echart (Project Norte-01-0247-FEDER024479). This study was financed in part by the Coordenação de Aperfeiçoamento de Pessoal de Nível Superior - Brasil (CAPES) Finance Code 001.

\section{References}

[1] P.A. McCarron, R.F. Donnelly, R. Al-Kassas, Comparison of a novel spray congealing procedure with emulsion-based methods for the microencapsulation of water-soluble drugs in low melting point triglycerides, J. Microencapsul. 25 (2008) 365-378, https://doi.org/10.1080/ 02652040802000656

[2] N. Passerini, B. Albertini, B. Perissutti, L. Rodriguez, Evaluation of melt granulation and ultrasonic spray congealing as techniques to enhance the dissolution of praziquantel, Int. J. Pharm. 318 (2006) 92-102, https://doi.org/ 10.1016/j.ijpharm.2006.03.028.

[3] M.M.S. Vieira, R.M. Martins, L.A.P. Freitas, Characteristics of piroxicam granules prepared by fluidized bed hot melt granulation, Adv. Powder Technol. 29 (2018) 934-940, https://doi.org/10.1016/j.apt.2018.01.011.

[4] K. Traub-Hoffmann, K. Gegenfurtner, K.U. Kraft, W. Friess, Spray congealed solid lipid microparticles as a sustained release delivery system for Gonadorelin [6-D-Phe]: Production, optimization and in vitro release behavior, Eur. J. Pharm. Biopharm. 154 (2020) 18-32, https://doi.org/ 10.1016/j.ejpb.2020.06.017.

[5] S. Scalia, D. Traini, P.M. Young M. Di Sabatino, N. Passerini, B. Albertini, Comparison of spray congealing and melt emulsification methods for the incorporation of the water-soluble salbutamol sulphate in lipid microparticles, Pharm. Dev. Technol. 18 (2013) 266-273, https://doi.org/10.3109/ 10837450.2012.717947.

[6] K. Tahara, Pharmaceutical formulation and manufacturing using particle/ powder technology for personalized medicines, Adv. Powder Technol. 31 (2020) 387-392, https://doi.org/10.1016/j.apt.2019.10.031.

[7] M. de S. Queirós, R.L.S. Viriato, A.P.B. Ribeiro, M.L. Gigante, Dairy-based solid lipid microparticles: A novel approach, Food Res. Int. 131 (2020), https://doi. org/10.1016/j.foodres.2020.109009.

[8] A. Tomšik, L. Šarić, S. Bertoni, M. Protti, B. Albertini, L. Mercolini, N. Passerini, Encapsulations of wild garlic (Allium ursinum L.) extract using spray congealing technology, Food Res. Int. 119 (2019) 941-950, https://doi.org/ 10.1016/j.foodres.2018.10.081.

[9] I. Katouzian, A. Faridi Esfanjani, S.M. Jafari, S. Akhavan, Formulation and application of a new generation of lipid nano-carriers for the food bioactive ingredients, Trends Food Sci. Technol. 68 (2017) 14-25, https://doi.org/ 10.1016/j.tifs.2017.07.017.

[10] F. Fratini, G. Cilia, B. Turchi, A. Felicioli, Beeswax: A minireview of its antimicrobial activity and its application in medicine, Asian Pac. J. Trop. Med. 9 (2016) 839-843, https://doi.org/10.1016/j.apjtm.2016.07.003.

[11] Y. Soleimanian, S.A.H. Goli, J. Varshosaz, S.M. Sahafi, Formulation and characterization of novel nanostructured lipid carriers made from beeswax, propolis wax and pomegranate seed oil, Food Chem. 244 (2018) 83-92, https://doi.org/10.1016/j.foodchem.2017.10.010.

[12] A.F. Harron, M.J. Powell, A. Nunez, R.A. Moreau, Analysis of sorghum wax and carnauba wax by reversed phase liquid chromatography mass spectrometry,
Ind. Crops Prod. 98 (2017) 116-129, https://doi.org/10.1016/j. indcrop.2016.09.015.

[13] C.-L. Fang, S.A. Al-Suwayeh, J.-Y. Fang, Nanostructured lipid carriers (NLCs) for drug delivery and targeting, Recent Pat. Nanotechnol. 7 (2013) 41-55, https:// doi.org/10.2174/1872210511307010041.

[14] J.J. DiNicolantonio, S.C. Lucan, J.H. O'Keefe, The evidence for saturated fat and for sugar related to coronary heart disease, Prog. Cardiovasc. Dis. 58 (2016) 464-472, https://doi.org/10.1016/j.pcad.2015.11.006.

[15] V. Da Silva Santos, A.P. Badan Ribeiro, M.H. Andrade Santana, Solid lipid nanoparticles as carriers for lipophilic compounds for applications in foods, Food Res. Int. 122 (2019) 610-626, https://doi.org/10.1016/ j.foodres.2019.01.032.

[16] A.S. Pedro, S.D. Villa, P. Caliceti, S.A.B.V. De Melo, E.C. Albuquerque, A. Bertucco, S. Salmaso, Curcumin-loaded solid lipid particles by PGSS technology, J. Supercrit. Fluids 107 (2016) 534-541, https://doi.org/10.1016/ j.supflu.2015.07.010.

[17] A.C. da Silva, P.D. de F. Santos, J.T. do P. Silva, F.V. Leimann, L. Bracht, O.H. Gonçalves, Impact of curcumin nanoformulation on its antimicrobial activity, Trends Food Sci. Technol. 72 (2018) 74-82, https://doi.org/10.1016/j. tifs.2017.12.004.

[18] S.K. Dubey, A.K. Sharma, U. Narain, K. Misra, U. Pati, Design, synthesis and characterization of some bioactive conjugates of curcumin with glycine, glutamic acid, valine and demethylenated piperic acid and study of their antimicrobial and antiproliferative properties, Eur. J. Med. Chem. 43 (2008) 1837-1846, https://doi.org/10.1016/j.ejmech.2007.11.027.

[19] R. Feng, Z. Song, G. Zhai, Preparation and in vivo pharmacokinetics of curcumin-loaded PCL-PEG-PCL triblock copolymeric nanoparticles, Int. J. Nanomedicine. 7 (2012) 4089-4098, https://doi.org/10.2147/IJN.S33607.

[20] J. Gómez-Estaca, M.P. Balaguer, G. López-Carballo, R. Gavara, P. HernándezMuñoz, Improving antioxidant and antimicrobial properties of curcumin by means of encapsulation in gelatin through electrohydrodynamic atomization, Food Hydrocoll. 70 (2017) 313-320, https://doi.org/10.1016/ j.foodhyd.2017.04.019.

[21] P. Govindaraj, B. Kandasubramanian, K.M. Kodam, Molecular interactions and antimicrobial activity of curcumin (Curcuma longa) loaded polyacrylonitrile films, Mater. Chem. Phys. 147 (2014) 934-941, https://doi.org/10.1016/ j.matchemphys.2014.06.040.

[22] J. Lal, S.K. Gupta, D. Thavaselvam, D.D. Agarwal, Biological activity, design, synthesis and structure activity relationship of some novel derivatives of curcumin containing sulfonamides, Eur. J. Med. Chem. 64 (2013) 579-588, https://doi.org/10.1016/j.ejmech.2013.03.012.

[23] A. Duvoix, R. Blasius, S. Delhalle, M. Schnekenburger, F. Morceau, E. Henry, M. Dicato, M. Diederich, Chemopreventive and therapeutic effects of curcumin, Cancer Lett. 223 (2005) 181-190, https://doi.org/10.1016/ j.canlet.2004.09.041.

[24] M.C. Fadus, C. Lau, J. Bikhchandani, H.T. Lynch, Curcumin: An age-old antiinflammatory and anti-neoplastic agent, J. Tradit. Complement. Med. 7 (2017) 339-346, https://doi.org/10.1016/j.jtcme.2016.08.002.

[25] H.T. Liu, Y.S. Ho, Anticancer effect of curcumin on breast cancer and stem cells, Food Sci. Hum. Wellness. 7 (2018) 134-137, https://doi.org/10.1016/j. fshw.2018.06.001.

[26] C. Ban, M. Jo, Y.H. Park, J.H. Kim, J.Y. Han, K.W. Lee, D.H. Kweon, Y.J. Choi, Enhancing the oral bioavailability of curcumin using solid lipid nanoparticles, Food Chem. 302 (2020), https://doi.org/10.1016/j.foodchem.2019.125328 125328.

[27] Y. Liu, D. Liu, L. Zhu, Q. Gan, X. Le, Temperature-dependent structure stability and in vitro release of chitosan-coated curcumin liposome, Food Res. Int. 74 (2015) 97-105, https://doi.org/10.1016/j.foodres.2015.04.024

[28] H. Abdulrahman, L. Misba, S. Ahmad, A.U. Khan, Curcumin induced photodynamic therapy mediated suppression of quorum sensing pathway of Pseudomonas aeruginosa: An approach to inhibit biofilm in vitro, Photodiagn. Photodyn. Ther. 30 (2020), https://doi.org/10.1016/j.pdpdt.2019.101645 101645.

[29] J.L.S. Gonçalves, S.R. Valandro, A.L. Poli, C.C. Schmitt, Influence of clay minerals on curcumin properties: Stability and singlet oxygen generation, J. Mol. Struct. 1143 (2017) 1-7, https://doi.org/10.1016/j.molstruc.2017.04.073.

[30] H.R. Park, S.J. Rho, Y.R. Kim, Solubility, stability, and bioaccessibility improvement of curcumin encapsulated using 4- $\alpha$-glucanotransferasemodified rice starch with reversible $\mathrm{pH}$-induced aggregation property, Food Hydrocoll. 95 (2019) 19-32, https://doi.org/10.1016/j.foodhyd.2019.04.012.

[31] Y.B. Tsaplev, V.A. Lapina, A.V. Trofimov, Curcumin in dimethyl sulfoxide: Stability, spectral, luminescent and acid-base properties, Dye. Pigment. 177 (2020), https://doi.org/10.1016/j.dyepig.2020.108327 108327.

[32] M.I.L. Neves, S. Desobry-Banon, I.T. Perrone, S. Desobry, J. Petit, Encapsulation of curcumin in milk powders by spray-drying: Physicochemistry, rehydration properties, and stability during storage, Powder Technol. 345 (2019) 601-607. https://doi.org/10.1016/j.powtec.2019.01.049.

[33] V.F. Leimann, O.H. Gonçalves, G.D. Sorita, S. Rezende, E. Bona, I.P.M. Fernandes, I.C.F.R. Ferreira, M.F. Barreiro, Heat and pH stable curcumin-based hydrophylic colorants obtained by the solid dispersion technology assisted by spraydrying, Chem. Eng. Sci. 205 (2019) 248-258, https://doi.org/10.1016/j. ces.2019.04.044.

[34] M. Burra, R. Jukanti, K.Y. Janga, S. Sunkavalli, A. Velpula, S. Ampati, K.N. Jayaveera, Enhanced intestinal absorption and bioavailability of raloxifene hydrochloride via lyophilized solid lipid nanoparticles, Adv. Powder Technol. 24 (2013) 393-402, https://doi.org/10.1016/j.apt.2012.09.002. 
[35] A. Berton, G. Piel, B. Evrard, Powdered lipid nano and microparticles: production and applications, Recent Pat. Drug Deliv. Formul. 5 (2011) 188200, https://doi.org/10.2174/187221111797200588.

[36] L. Battaglia, M. Gallarate, Lipid nanoparticles: State of the art, new preparation methods and challenges in drug delivery, Expert Opin. Drug Deliv. 9 (2012) 497-508, https://doi.org/10.1517/17425247.2012.673278.

[37] S. Bertoni, D. Tedesco, M. Bartolini, C. Prata, N. Passerini, B. Albertini, Solid lipid microparticles for oral delivery of catalase: focus on the protein structural integrity and gastric protection, Mol. Pharm. 17 (2020) 3609-3621, https://doi. org/10.1021/acs.molpharmaceut.0c00666.

[38] S. Bertoni, B. Albertini, C. Facchini, C. Prata, N. Passerini, Glutathione-loaded solid lipid microparticles as innovative delivery system for oral antioxidant therapy, Pharmaceutics. 11 (1-17) (2019) 364, https://doi.org/10.3390/ pharmaceutics 11080364

[39] R.E. Bruns, I.S. Scarminio, B. De Barros Neto, Statistical design - chemometrics, Amsterdam, 2006.

[40] M.M.L. Tormena, L.T. de Medeiros, P.C. de Lima, G. Possebon, R.H.B. Fuchs, E. Bona, Application of multi-block analysis and mixture design with process variable for development of chocolate cake containing yacon (Smallanthus sonchifolius) and maca (Lepidium meyenii), J. Sci. Food Agric. 97 (2017) 35593567, https://doi.org/10.1002/jsfa.8211.

[41] A. Guimarães-Inácio, C.R.L. Francisco, V.M. Rojas, R. de S. Leone, P. Valderrama, E. Bona, F.V. Leimann, A.A.C. Tanamati, O.H. Gonçalves, Evaluation of the oxidative stability of chia oil-loaded microparticles by thermal, spectroscopic and chemometric methods, LWT - Food Sci. Technol. 87 (2018) 498-506, https://doi.org/10.1016/j.lwt.2017.09.031.

[42] K.C. Kaufmann, O.H. Gonçalves, E. Bona, F.V. Leimann, Modelling the melting temperature of a lipid-based critical temperature indicator: A comparision between simplex-lattice and simplex-centroid designs, Bol. Cent. Pesqui. Process. Aliment. 35 (2017) 1-10, https://doi.org/10.5380/bceppa. v35i2.60305.

[43] R. Couto, V. Alvarez, F. Temelli, Encapsulation of vitamin B2 in solid lipid nanoparticles using supercritical CO2, J. Supercrit. Fluids 120 (2017) 432-442, https://doi.org/10.1016/j.supflu.2016.05.036.

[44] A. Alfutimie, N. Al-Janabi, R. Curtis, G.J.T. Tiddy, The effect of monoglycerides on the crystallisation of triglyceride, Colloids Surf. A Physicochem. Eng. Asp. 494 (2016) 170-179, https://doi.org/10.1016/j.colsurfa.2016.01.029.

[45] J. Liu, Q. Hui Zhang, F. Ma, S. Feng Zhang, Q. Zhou, A. Min Huang, Three-step identification of infrared spectra of similar tree species to Pterocarpus santalinus covered with beeswax, J. Mol. Struct. 1218 (2020) 128484, https://doi.org/10.1016/j.molstruc.2020.128484.

[46] Y. Zhang, B.K. Simpson, M.J. Dumont, Effect of beeswax and carnauba wax addition on properties of gelatin films: A comparative study, Food Biosci. 26 (2018) 88-95, https://doi.org/10.1016/j.fbio.2018.09.011.

[47] I.D. Alvim, M.A. Stein, I.P. Koury, F.B.H. Dantas, C.L. de C.V. Cruz, Comparison between the spray drying and spray chilling microparticles contain ascorbic acid in a baked product application, LWT - Food Sci. Technol. 65 (2016) 689694, https://doi.org/10.1016/j.lwt.2015.08.049.

[48] H.N.M. Chambi, I.D. Alvim, D. Barrera-Arellano, C.R.F. Grosso, Solid lipid microparticles containing water-soluble compounds of different molecular mass: Production, characterisation and release profiles, Food Res. Int. 41 (2008) 229-236, https://doi.org/10.1016/j.foodres.2007.11.012.

[49] L. Consoli, R. Grimaldi, T. Sartori, F.C. Menegalli, M.D. Hubinger, Gallic acid microparticles produced by spray chilling technique: Production and characterization, LWT - Food Sci. Technol. 65 (2016) 79-87, https://doi.org/ 10.1016/j.lwt.2015.07.052.

[50] R. Wegmüller, M.B. Zimmermann, V.G. Bühr, E.J. Windhab, R.F. Hurrell, Development, stability, and sensory testing of microcapsules containing iron, iodine, and vitamin A for use in food fortification, Sens. Nutr. Qual. Food Dev. 71 (2006) S181-S187.

[51] B. Albertini, N. Passerini, F. Pattarino, L. Rodriguez, New spray congealing atomizer for the microencapsulation of highly concentrated solid and liquid substances, Eur. J. Pharm. Biopharm. 69 (2008) 348-357, https://doi.org/ 10.1016/j.ejpb.2007.09.011.

[52] F.E. Matos-Jr, M. Di Sabatino, N. Passerini, C.S. Favaro-Trindade, B. Albertini, Development and characterization of solid lipid microparticles loaded with ascorbic acid and produced by spray congealing, Food Res. Int. 67 (2015) 5259, https://doi.org/10.1016/j.foodres.2014.11.002.

[53] L.C. Massimino, H.A.M. Faria, S.A. Yoshioka, Curcumin bioactive nanosizing: Increase of bioavailability, Ind. Crops Prod. 109 (2017) 493-497, https://doi. org/10.1016/j.indcrop.2017.09.001.

[54] N. Tanner, B. Lichtenberg-Kraag, Identification and quantification of single and multi-adulteration of beeswax by FTIR-ATR spectroscopy, Eur. J. Lipid Sci. Technol. 121 (2019) 1-10, https://doi.org/10.1002/ejlt.201900245.

[55] R. Zhang, W. Wang, H. Zhang, Y. Dai, H. Dong, L. Kong, H. Hou, Effects of preparation conditions on the properties of agar/maltodextrin-beeswax pseudo-bilayer films, Carbohydr. Polym. 236 (2020), https://doi.org/10.1016/ j.carbpol.2020.116029 116029.

[56] D. Muscat, M.J. Tobin, Q. Guo, B. Adhikari, Understanding the distribution of natural wax in starch-wax films using synchrotron-based FTIR (S-FTIR), Carbohydr. Polym. 102 (2014) 125-135, https://doi.org/10.1016/ j.carbpol.2013.11.004.

[57] C. Butstraen, F. Salaün, Preparation of microcapsules by complex coacervation of gum Arabic and chitosan, Carbohydr. Polym. 99 (2014) 608-616, https://doi. org/10.1016/j.carbpol.2013.09.006.
[58] J. Milanovic, V. Manojlovic, S. Levic, N. Rajic, V. Nedovic, B. Bugarski, Microencapsulation of flavors in carnauba wax, Sensors. 10 (2010) 901-912, https://doi.org/10.3390/s100100901.

[59] H.H.S. Almeida, L. Barros, J.C.M. Barreira, R.C. Calhelha, S.A. Heleno, C. Sayer, C. G. Miranda, F.V. Leimann, M.F. Barreiro, I.C.F.R. Ferreira, Bioactive evaluation and application of different formulations of the natural colorant curcumin (E100) in a hydrophilic matrix (yogurt), Food Chem. 261 (2018) 224-232, https://doi.org/10.1016/j.foodchem.2018.04.056.

[60] G.F. Lemes, N.G. Marchiore, T.F.M. Moreira, T.B.V. Da Silva, C. Sayer, M.A. Shirai, O.H. Gonçalves, A.M. Gozzo, F.V. Leimann, Enzymatically crosslinked gelatin coating added of bioactive nanoparticles and antifungal agent: Effect on the quality of Benitaka grapes, LWT - Food -Science Technol. 84 (2017) 175-182, https://doi.org/10.1016/j.lwt.2017.05.050.

[61] R.A. Da Silva-Buzanello, M.F. De Souza, D.A. De Oliveira, E. Bona, F.V. Leimann, L.C. Filho, P.H.H. De Araújo, S.R.S. Ferreira, O.H. Gonçalves, Preparation of curcumin-loaded nanoparticles and determination of the antioxidant potential of curcumin after encapsulation, Polimeros. 26 (2016) 207-214, https://doi. org/10.1590/0104-1428.2246.

[62] W.H. Khan, V.K. Rathod, Process intensification approach for preparation of curcumin nanoparticles via solvent-nonsolvent nanoprecipitation using spinning disc reactor, Chem. Eng. Process. Process Intensif. 80 (2014) 1-10, https://doi.org/10.1016/j.cep.2014.03.011.

[63] J.M. Bailey, Nomenclature and classification of lipids, Food Lipids: Chem., Nutr. Biotechnol. (1999), https://doi.org/10.1021/ja985682t.

[64] C.C. Chu, Z.A.B.A. Hasan, S.K. Chua, K.L. Nyam, Formulation and characterization of novel nanostructured lipid carriers with photoprotective properties made from carnauba wax, beeswax, pumpkin seed oil, and UV filters, J. Am. Oil Chem. Soc. 97 (2020) 531-542, https://doi.org/10.1002/ aocs. 12340 .

[65] P. Ramalingam, S.W. Yoo, Y.T. Ko, Nanodelivery systems based on mucoadhesive polymer coated solid lipid nanoparticles to improve the oral intake of food curcumin, Food Res. Int. 84 (2016) 113-119, https://doi.org/ 10.1016/j.foodres.2016.03.031.

[66] E.S. Behbahani, M. Ghaedi, M. Abbaspour, K. Rostamizadeh, Optimization and characterization of ultrasound assisted preparation of curcumin-loaded solid lipid nanoparticles: Application of central composite design, thermal analysis and X-ray diffraction techniques, Ultrason. Sonochem. 38 (2017) 271-280, https://doi.org/10.1016/j.ultsonch.2017.03.013.

[67] M. Amin, N. Putra, E.A. Kosasih, E. Prawiro, R.A. Luanto, T.M.I. Mahlia, Thermal properties of beeswax/graphene phase change material as energy storage for building applications, Appl. Therm. Eng. 112 (2017) 273-280, https://doi.org/ 10.1016/j.applthermaleng.2016.10.085.

[68] A. Dinker, M. Agarwal, G.D. Agarwal, Experimental study on thermal performance of beeswax as thermal storage material, Mater. Today: Proc. 4 (2017) 10529-10533, https://doi.org/10.1016/j.matpr.2017.06.414.

[69] M.O. Reis, J.B. Olivato, A.P. Bilck, J. Zanela, M.V.E. Grossmann, F. Yamashita, Biodegradable trays of thermoplastic starch/poly (lactic acid) coated with beeswax, Ind. Crops Prod. 112 (2018) 481-487, https://doi.org/10.1016/j. indcrop.2017.12.045.

[70] J.R. Villalobos-Hernández, C.C. Müller-Goymann, Sun protection enhancement of titanium dioxide crystals by the use of carnauba wax nanoparticles: The synergistic interaction between organic and inorganic sunscreens at nanoscale, Int. J. Pharm. 322 (2006) 161-170, https://doi.org/10.1016/j. ijpharm.2006.05.037.

[71] M. Rahimzadeh, M. Sadeghizadeh, F. Najafi, S.S. Arab, P.S. Pourhosseini, Application of a novel pH-responsive gemini surfactant for delivery of curcumin molecules, Mater. Res. Express 7 (1-17) (2020) 065403, https:// doi.org/10.1088/2053-1591/ab770f.

[72] I. Silva de Sá, A.P. Peron, F.V. Leimann, G.N. Bressan, B.N. Krum, R. Fachinetto, J. Pinela, R.C. Calhelha, M.F. Barreiro, I.C.F.R. Ferreira, O.H. Gonçalves, R.P. Ineu, In vitro and in vivo evaluation of enzymatic and antioxidant activity, cytotoxicity and genotoxicity of curcumin-loaded solid dispersions, Food Chem. Toxicol. 125 (2019) 29-37, https://doi.org/10.1016/j.fct.2018.12.037.

[73] A. Patel, Y. Hu, J.K. Tiwari, K.P. Velikov, Synthesis and characterisation of zeincurcumin colloidal particles, Soft Matter 6 (2010) 6192-6199, https://doi.org/ 10.1039/c0sm00800a.

[74] M. Maria Leena, M. Gover Antoniraj, J.A. Moses, C. Anandharamakrishnan, Three fluid nozzle spray drying for co-encapsulation and controlled release of curcumin and resveratrol, J. Drug Deliv. Sci. Technol. 57 (2020), https://doi.org/ 10.1016/j.jddst.2020.101678 101678.

[75] C. Mohanty, S.K. Sahoo, The in vitro stability and in vivo pharmacokinetics of curcumin prepared as an aqueous nanoparticulate formulation, Biomaterials 31 (2010) 6597-6611, https://doi.org/10.1016/j.biomaterials.2010.04.062.

[76] A. Tasch Holkem, C.S. Favaro-Trindade, Potential of solid lipid microparticles covered by the protein-polysaccharide complex for protection of probiotics and proanthocyanidin-rich cinnamon extract, Food Res. Int. 136 (2020), https://doi.org/10.1016/j.foodres.2020.109520 109520.

[77] J.D. dos S. Carvalho, V.B. Oriani, G.M. de Oliveira, M.D. Hubinger, Characterization of ascorbic acid microencapsulated by the spray chilling technique using palm oil and fully hydrogenated palm oil, Lwt. 101 (2019) 306-314, https://doi.org/10.1016/j.lwt.2018.11.043. 